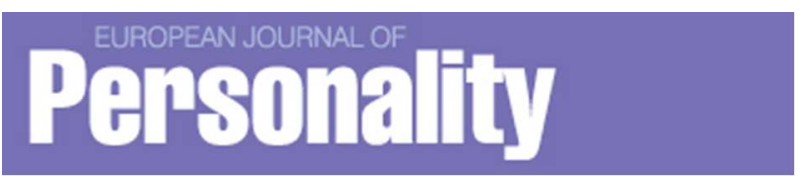

\title{
Development of indirect measures of conscientiousness: combining a facets approach and network analysis.
}

\begin{tabular}{|r|l|}
\hline Journal: & European Journal of Personality \\
\hline Manuscript ID: & EJP-15-1914.R1 \\
\hline Wiley - Manuscript type: & Research Article \\
\hline Complete List of Authors: & $\begin{array}{l}\text { Costantini, Giulio; University of Milan-Bicocca, Department of Psychology } \\
\text { RICHETIN, Juliette; University of Milan-Bicocca, Department of Psychology } \\
\text { Borsboom, Denny; University of Amsterdam, Department of Psychological } \\
\text { Methods } \\
\text { Fried, Eiko; University of Leuven, Faculty of Psychology and Educational } \\
\text { Sciences } \\
\text { Rhemtulla, Mijke; University of Amsterdam, Department of Psychological } \\
\text { Methods } \\
\text { perugini, Marco; University of Milan - Bicocca, Department of Psychology }\end{array}$ \\
\hline Manuscript Keywords: & $\begin{array}{l}\text { Implicit Association Test, conscientiousness facets, working memory, self- } \\
\text { control, network analysis }\end{array}$ \\
\hline
\end{tabular}


Development of indirect measures of conscientiousness: combining a facets approach and network analysis.

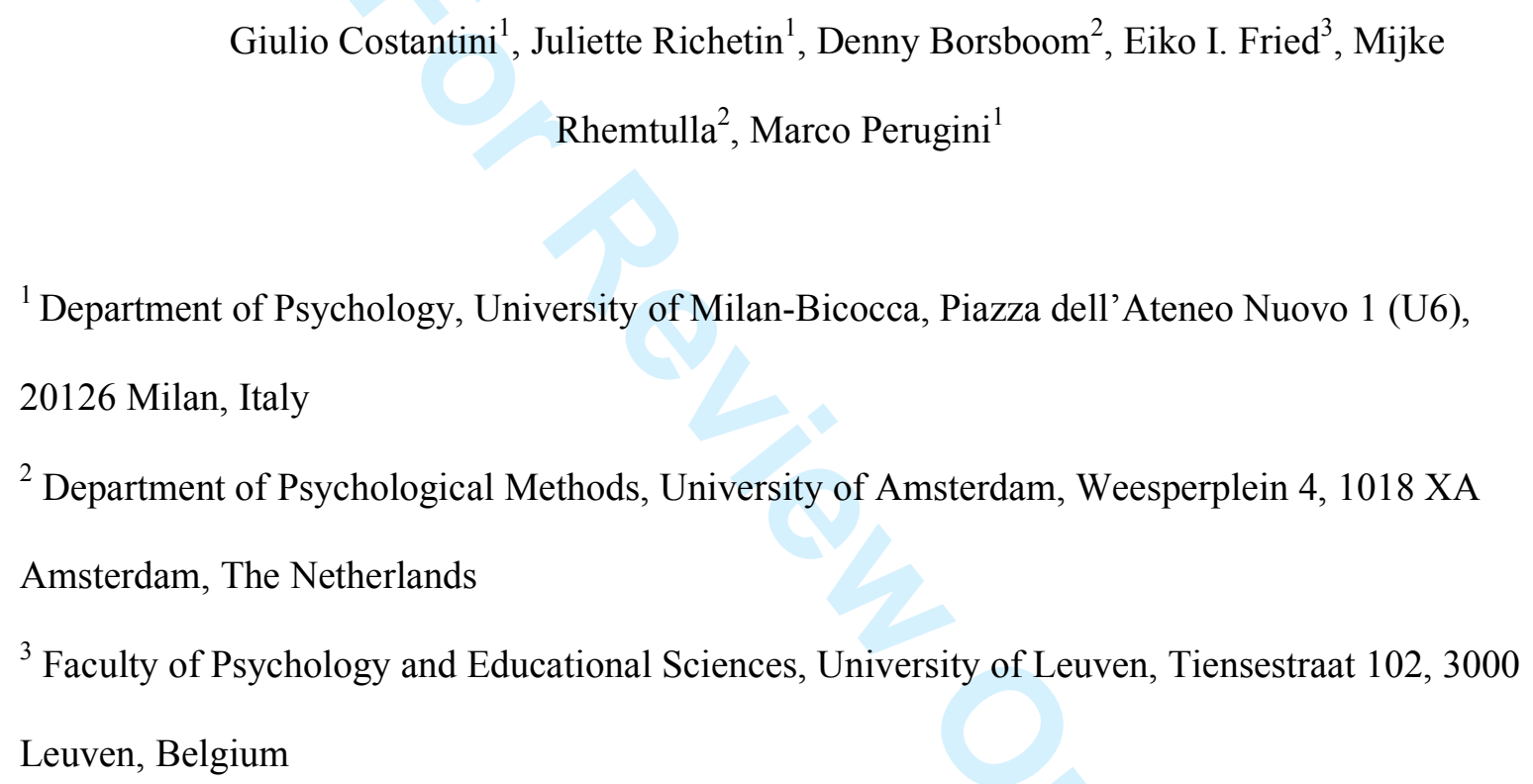

${ }^{1}$ Department of Psychology, University of Milan-Bicocca, Piazza dell'Ateneo Nuovo 1 (U6), 20126 Milan, Italy

${ }^{2}$ Department of Psychological Methods, University of Amsterdam, Weesperplein 4, 1018 XA Amsterdam, The Netherlands

${ }^{3}$ Faculty of Psychology and Educational Sciences, University of Leuven, Tiensestraat 102, 3000 Leuven, Belgium

This research was supported by Fondazione Cariplo research Grant "Dottorato ad alta formazione in Psicologia Sperimentale e Neuroscienze Cognitive" (Advanced education doctorate in experimental psychology and cognitive neurosciences), Grant Number 2010-1432.

Correspondence concerning this article should be addressed to Giulio Costantini, giulio.costantini@unimib.it, phone: +390264483867. 


\begin{abstract}
Because indirect measures of personality self-concepts such as the Implicit Association Test (IAT) allow tapping into automatic processes, they can offer advantages over self-report measures. However, prior investigations have led to mixed results regarding the validity of indirect measures of conscientiousness. We suggest that these results might be due to a failure to consider the different facets of conscientiousness. These facets are of crucial importance because are associated differentially with other psychobiological constructs and they are also characterized by different mechanisms. Therefore, focusing on facets while developing indirect measures of conscientiousness may improve the validity of such measures. In Study 1 we conducted a psycholexical investigation to develop one IAT for each conscientiousness facet. In Study 2, we examined the convergent and discriminant validities of each facet IAT in relation to self-report measures, peer-report measures, and self-report behavioral indicators, and we investigated differential associations of the conscientiousness facets with working memory capacity and self-control. We employed network analysis as a novel approach to elucidate differential relationships involving personality facets. The results corroborated the convergent and discriminant validity of the conscientiousness facets IATs with self-reports and showed that the conscientiousness facets were differentially associated with working memory capacity and with self-control.
\end{abstract}

Keywords: Implicit Association Test, conscientiousness facets, working memory, self-control, network analysis 
Development of indirect measures of conscientiousness: combining a facets approach and network analysis.

Conscientiousness is a broad trait included in most taxonomies of personality, such as the Big Five (Goldberg, 1993; John \& Srivastava, 1999) and the HEXACO model (Ashton et al., 2006; Ashton, Lee, Perugini, et al., 2004; Lee \& Ashton, 2008; Saucier, 2009). Conscientiousness is defined as the "socially prescribed impulse control that facilitates task- and goal-directed behavior, such as thinking before acting, delaying gratification, following norms and rules, and planning, organizing and prioritizing tasks” (John \& Srivastava, 1999, p. 121). Several studies have investigated the lower-level facet structure of conscientiousness using self-report measures (Jackson et al., 2010; MacCann, Duckworth, \& Roberts, 2009; Peabody \& De Raad, 2002; Perugini \& Gallucci, 1997; Roberts, Bogg, Walton, Chernyshenko, \& Stark, 2004; Roberts, Chernyshenko, Stark, \& Goldberg, 2005). Up to ten different facets have been identified in different studies (cf. Roberts, Lejuez, Krueger, Richards, \& Hill, 2014). Among these, four main facets have been recovered in a consistent way, albeit with slightly different labels, and are industriousness, impulse-control, orderliness, and responsibility ${ }^{1}$ (e.g., Roberts et al., 2014, Table $1)$.

It is important to notice that, at this finer-grained level of personality structure, consensus among scholars is less pronounced, and which of the facets is included in a questionnaire depends largely on theoretical considerations and inclinations of the authors. For example, the NEO-PI-R (Costa \& McCrae, 1992) includes six facets of conscientiousness. However, when analyzed together with facets of conscientiousness taken from other main personality questionnaires, these

\footnotetext{
${ }^{1}$ Responsibility has been also considered as a blend of conscientiousness and agreeableness (e.g., Roberts et al., 2004; 2014).
} 
six facets of the NEO-PI-R tap into only three of the main general facets of conscientiousness: Order loads on an orderliness factor, deliberation loads on impulse-control, and dutifulness, achievement striving, competence, and self-discipline load on industriousness (Roberts et al., 2005). Therefore, among the main four facets, industriousness is over-represented in the NEO-PI$\mathrm{R}$, whereas responsibility is not represented at all. Similarly, a theoretical analysis of the four conscientiousness facets of the HEXACO-PI (Lee \& Ashton, 2004) reveals that none of them reflects the facet of responsibility. As we will argue below, these choices have important ramifications for the evaluation of conscientiousness research.

In terms of construct assessment and behavioral prediction, conscientiousness has been widely investigated. For example, on the basis of analyses of self-reports, conscientiousness has been shown to be a consistent predictor of several important life outcomes such as health (Bogg \& Roberts, 2004; Friedman \& Kern, 2014; Roberts, Walton, \& Bogg, 2005), longevity (Kern \& Friedman, 2008), academic performance (Poropat, 2009), and job performance (Barrick \& Mount, 1991).

In addition to self-reports, indirect measures ${ }^{2}$ have been developed to assess personality constructs such as conscientiousness, consistent with many theoretical models postulating that human behavior is influenced by deliberative and automatic processes (Back, Schmukle, \& Egloff, 2009; Deutsch \& Strack, 2010; Evans, 2008; Gawronski \& Bodenhausen, 2007; Gawronski, Sherman, \& Trope, 2014; Strack \& Deutsch, 2004). In the general domain of personality, as well as in other domains, the Implicit Association Test (IAT; Greenwald, McGhee, \& Schwartz, 1998) shows acceptable validity and reliability (Bar-Anan \& Nosek, 2014; Egloff, Schwerdtfeger, \& Schmukle, 2005; Greenwald, Poehlman, Uhlmann, \& Banaji, 2009;

\footnotetext{
${ }^{2}$ We use the term indirect and direct rather than implicit and explicit measures in line with the arguments and definitions of De Houwer and Moors (2010).
} 
Hofmann, Gawronski, Gschwendner, Le, \& Schmitt, 2005; Nosek, 2007; but see Blanton, Jaccard, Gonzales, \& Christie, 2006). The IAT has been used to assess the Big Five (Back et al., 2009; Grumm \& von Collani, 2007; Schmukle, Back, \& Egloff, 2008; Steffens \& König, 2006) along with specific traits such as shyness (Asendorpf, Banse, \& Mücke, 2002), anxiety (Egloff \& Schmukle, 2002), morality (Perugini \& Leone, 2009), and aggressiveness (Richetin, Richardson, \& Mason, 2010).

In terms of predictive validity, personality IATs can perform better in the prediction of spontaneous and objective behaviors than self-reported behaviors (Asendorpf et al., 2002; Egloff \& Schmukle, 2002; Perugini \& Leone, 2009; Steffens \& König, 2006). In the specific domain of conscientiousness, however, the validity of indirect measures has received mixed empirical support. Indirect measures of conscientiousness showed convergent validity with self-report measures in some studies (Grumm \& von Collani, 2007; Schmukle et al., 2008; Steffens \& König, 2006), but not others (Back et al., 2009; Vianello, Robusto, \& Anselmi, 2010). In a similar vein, although some research has demonstrated criterion validity of indirect measures of conscientiousness for particular behavioral criteria (e.g., the performance in a test of attention, Steffens \& König, 2006; the number of exams succesfully passed, Vianello et al., 2010), an extensive report including several behavioral criteria found no evidence of such validity (Back et al., 2009).

The lack of agreement in prior studies may stem from the fact that each study has measured conscientiousness using different stimuli linked to a different constellation of specific facets. For instance, some authors (e.g., Steffens \& König, 2006) primarily assessed industriousness (strong-willed, disciplined, aimless, and laid-back), orderliness (i.e., pedantic, organized, chaotic, and untidy) and to a lesser extent, responsibility (dependable and late) and impulse-control (disciplined). Others (e.g., Back et al., 2009), however, mainly assessed 
orderliness (meticulous, neat, fussy, thorough, chaotic, and careless) and, to a lesser extent, responsibility (reliable and unreliable), without taking into account industriousness and impulsecontrol $^{3}$. It has been shown the choice of particular stimuli can substantially influence the IAT effect (Bluemke \& Friese, 2006; Govan \& Williams, 2004), suggesting that the mixed results could be due to the fact that these researchers assessed different things under the same label.

Prior studies appear to be based on the notion that all measures in the conscientiousness domain are exchangeable, as they might in fact be if they all depended on a single latent variable (Cramer, Waldorp, Van der Maas, \& Borsboom, 2010). However, research does not support the exchangeability of conscientiousness measures, because the facets of conscientiousness play divergent and specific roles with respect to other traits and behavioral outcomes.

Conscientiousness facets have distinguishable precursors in childhood (see Eisenberg et al., 2014 for a review), change differently over the course of life (Jackson et al., 2009; Mõttus et al., 2015; Soto \& John, 2012), and have differential relationships with other variables (e.g., Moon, 2001; Perry, Hunter, Witt, \& Harris, 2010; Ruiz, Pincus, \& Dickinson, 2003). This has been explained as the effect of narrower personality mechanisms that characterize only some conscientiouness facets, but not the whole dimension (Soto \& John, 2012). As a consequence, considering facets improves the prediction of important criteria such as academic performance and health (Ashton, 1998; Bogg \& Roberts, 2004; O’Connor \& Paunonen, 2007; Paunonen \& Ashton, 2001, 2013; Paunonen, 1998) and it results in finer grained personality profiles (Costa \& McCrae, 1995). Here, we argue that studying conscientiousness as if it was a unidimensional latent variable may hinder a thorough understanding of its mechanisms and it may mask important differential roles played by specific facets, especially in relation to indirect measures.

\footnotetext{
${ }^{3}$ Two additional stimuli, frivolous and erratic, tapped into more general aspects of conscientiousness that could not be univocally classified in the four facets structure of conscientiousness.
} 
An explanation of the lack of validity of some personality IATs, which does not involve facets, has been put forward by Back and colleagues. According to the Behavior Process Model of Personality (Back et al., 2009) the implicit self-concept of personality consists in a set of connections between the self and other elements of an associative network (e.g., "me""meticulous" or "me"-“chaotic"), which form as a consequence of the repeated activation of the self together with automatic motivational tendencies (e.g., approach and avoidance) and impulsive behaviors. Back and colleagues noticed that conscientiousness may involve less impulsive processes than other traits (Back et al., 2009, footnote 6), therefore valid indirect measures of conscientiousness could be difficult to develop. We argue that Back's argument can be qualified by considering conscientiousness facets and their differential relationships with other constructs. Conscientiousness correlates with both promotion and prevention focus (Gorman et al., 2012; Lanaj, Chang, \& Johnson, 2012), which are motivational tendencies connected to approach and avoidance (Higgins, 1997), and from its very origins it is also strongly connected with impulsivity and self-control (e.g., Eisenberg et al., 2014; MacDonald, 2008; Sharma, Markon, \& Clark, 2014). However conscientiousness facets have differential relationships with impulsivity, with facets such as industriousness and impulse-control being more clearly related with aspects of impulsivity than facet orderliness (e.g., Sharma, Markon, \& Clark, 2014). Since most of the markers used by Back and colleagues in the conscientiousness IAT assessed orderliness and responsibility, their measure may not have reflected aspects of impulsivity, which nonetheless characterize conscientiousness. Back and colleagues recognize that their "results do not definitely exclude the possibility that using other indirect measures of openness and conscientiousness (particularly those highlighting the potentially impulsive aspects of the traits) might help to predict actual behavior" (Back et al., 2009, p. 543). Similarly, we argue that considering facets when developing conscientiousness IATs may result in more valid measures 
and it may also help to clarify the connections between implicit conscientiousness and impulsivity / self-control. It should be also noticed that even for traits that do not involve impulsive motivational and behavioral tendencies, the additional value of considering indirect measures besides self-reports comes from the lower sensitivity of indirect measures to socially desirable responding and to limits in the introspective ability (e.g., Greenwald et al., 2002, 2009). For instance self-esteem would not seem to entail clear impulsive motivational and behavioral tendencies, nonetheless it can be validly assessed using the IAT (Greenwald \& Farnham, 2000) and its mechanisms can be conceptualized more clearly if one considers both direct and indirect measures (Zeigler-Hill, 2006).

The main aim of this contribution was (1) developing an indirect assessment of conscientiousness with a focus on its facets and testing its convergent and discriminant validity. Additionally, we investigated the connections between conscientiousness facets and (2) selfcontrol and (3) working memory capacity, with a focus on a more accurate assessment using both direct and indirect measures. We selected self-control and working memory because they are suitable targets to study potential differential aspects of conscientiousness facets. The last aim of the study was to (4) exemplify how network analysis can be used as method for grasping the complex pattern of relationships among several variables in personality research. In the following we detail the rationale of each aim.

\section{Aim 1: Development of indirect measures of conscientiousness and test of convergent and discriminant validity}

In the light of the differences in stimuli selection emerged in previous studies, we performed a first attempt of developing a valid conscientiousness IAT by selecting stimuli that covered different facets of conscientiousness as uniformly as possible. Despite this more systematic selection of stimuli, the IAT did not correlate with self-report measures of 
conscientiousness (full details about this study can be found in the Supplementary Materials S1). This motivated us to follow a different approach, based on a more distinct consideration of facets. Instead of developing a single conscientiousness IAT, we decided to develop four different IATs, one for each of the main conscientiousness facets that have been consensually identified in the literature-industriousness, impulse-control, orderliness, and responsibility.

The development of several IATs to assess specific facets of a personality domain has not been attempted before and poses a new challenge. Since different facets are expected to correlate strongly with each other, inaccuracies in selecting the stimuli for the IATs may result in all of the measures assessing the same superordinate dimension (conscientiousness) without clearly discriminating its facets. Therefore, rather than selecting stimuli on the basis of expert judgment, as usually done in IAT studies, we carefully selected the markers to be used as stimuli by means of a dedicated psycholexical study (Ashton \& Lee, 2005; De Raad et al., 2014; Goldberg, 1990; Saucier et al., 2014).

The first and most important test of convergent validity was performed with respect to self-report measures. Additionally, we investigated whether the IAT converged also with peerreports and with self-report behavioral indicators connected to specific facets of conscientiousness. Convergent and discriminant validity provides an important indicator of the goodness of indirect measures: A meta-analysis has shown that the IATs that converge with corresponding self-report measures have also better criterion validity (Greenwald, Poehlman, Uhlman, \& Banaji, 2009) and this seems to be true in particular for self-concept IATs. In the study by Back and colleagues (2009) the neuroticism and extraversion IATs, which converged with self-reports, also showed predictive and incremental validity, while other IATs that did not converge with self-reports did not predict behavior. Furthermore, although it is usually assumed that the structure of broad implicit personality traits is akin to the structure that emerges from 
self-reports (e.g., a Big Five structure, Back et al., 2009; Grumm \& von Collani, 2007; Schmukle et al., 2008; Steffens \& König, 2006), one cannot exclude that differences between the structure of the explicit and the implicit personality may be more pronounced at the level of facets. Convergent and discriminant validity would indicate that the facets assessed at the implicit level correspond to the facets that emerge from self-reports, while absence of convergent and discriminant validity would indicate that some of these facets are difficult to recover at the implicit level.

\section{Aim 2: Conscientiousness and self-control}

Self-control is the "exertion of control over the self by the self" (Muraven \& Baumeister, 2000, p. 247) that can be enacted by actively resisting temptations (Baumeister, Vohs, \& Tice, 2007) or by avoiding them (Ent, Baumeister, \& Tice, 2015). Two main aspects of self-control have been distinguished (De Boer et al., 2011): Start-control is the proactive component of selfcontrol which allows people to initiate desirable behavior, and stop-control is the inhibitory component which obstructs undesirable behavior. Self-control is one of the most important correlates of conscientiousness (de Vries \& van Gelder, 2013; Roberts et al., 2014; Tangney, Baumeister, \& Boone, 2004), and early self-regulatory abilities have a key role in the development of conscientiousness (Eisenberg, Duckworth, Spinrad, \& Valiente, 2014; MacDonald, 2008; Roberts et al., 2014).

Investigating both conscientiousness and self-control by considering their facets might shed further light on their relationships. On the one hand industriousness and impulse-control are closely connected to pursuing goals and resisting temptations respectively (e.g., Jackson et al., 2010): We hypothesize that industriousness will be more clearly associated with start-control, while impulse-control should be strongly related with stop-control. On the other hand, we expect that the associations between the two aspects of self-control and the other facets of 
conscientiousness-such as orderliness and responsibility-should be weaker, since these facets do not entail specifically resisting or avoiding temptations.

\section{Aim 3: Conscientiousness and working memory capacity}

We aimed at investigating the relationships between conscientiousness facets and working memory. Working memory is a multicomponent system which is responsible for maintaining and processing information in the face of distraction (Baddeley \& Hitch, 1974; Baddeley, 1992; Conway et al., 2005) and has a high degree of overlap with the concept of executive functioning (McCabe, Roediger, McDaniel, Balota, \& Hambrick, 2010; Miyake et al., 2000). Previous studies that investigated the relationship between conscientiousness and working memory observed null results (Fleming, Heintzelman, \& Bartholow, 2015; Murdock, Oddi, \& Bridgett, 2013; Unsworth et al., 2009; Williams, Suchy, \& Kraybill, 2010). We suggest that the connections between conscientiousness and working memory could be further elucidated by a systematic consideration of the facets of conscientiousness.

\section{Aim 4: Network Analysis}

The last aim of our work was showing how network analysis can be used for analyzing personality data. The network approach has only recently been added to the toolbox of the personality investigator (Cramer et al., 2012; for introductions to network analysis, see for instance de Nooy, Mrvar, and Batagelj, 2011; Kolaczyk, 2009; Newman, 2010). A network is a representation of a group of entities and their relationships as a set of nodes and a set of edges that connect the nodes: Networks are used to represent and study many diverse phenomena in several fields of science such as genomics (e.g., Zhang \& Horvath, 2005), economics (e.g., Iori, De Masi, Precup, Gabbi, \& Caldarelli, 2008), and medicine (e.g., Hopkins, 2008). Networks of interactions among affects, cognitions, and behaviors have been proposed as an alternative model of personality that does not require latent variables (Cramer et al., 2012): According to the 
network perspective, the coalescence of observable variables into traits is the consequence of the interactions that take place within such networks (Costantini et al., 2015).

Networks can be used to grasp the complex interplay among several variables in personality studies. In personality networks nodes typically represent variables such as items or facets, and edges represent their pairwise associations (Costantini et al., 2015; Cramer et al., 2012). The adaptive lasso method (Costantini et al., 2015; Krämer, Schäfer, \& Boulesteix, 2009) attempts to reconstruct the true population network of partial relationships that gave rise to the observed correlations by constraining some edges to be exactly zero, while maintaining good fit with the data. The computation of an adaptive lasso network is performed in three main steps. First each variable is regressed on all others using a lasso penalty (Tibshirani, 1996), which causes small regression coefficients to shrink to be exactly zero. At the second stage, each variable is regressed on all others again, this time using an adaptive lasso penalty. The adaptive lasso penalty includes both a lasso penalty and different penalty weights for each coefficient (Zou, 2006), which are computed as the inverse of the regression coefficients computed at the first stage. This results in even more regression coefficients to shrink to zero. The regression coefficients computed at the second stage are then used for reconstructing a matrix of partial correlations, which represents the relationships between any two variables when the other relevant variables are partialled out. Each partial correlation defines an edge in the network, therefore if an edge connects two nodes, one can conclude that the corresponding constructs are associated and that their association cannot be completely attributed to the other variables, whereas if a link is missing between two variables they can be considered independent given the others (for further details on the method, see Krämer, Schäfer, \& Boulesteix, 2009; for an application to personality, see Costantini et al. 2015). Adaptive lasso networks can be particularly 
effective for investigating differential relationships characterizing variables that are correlated but distinguishable, such as personality facets (Costantini et al., 2015).

\section{Study 1: Development of Stimuli for IATs}

We adopted a psycholexical approach to select the best markers for each of the four facets to be used in the IATs. Stimuli are often selected based on intuition, without specific empirical evidence of their adequacy to reflect the targeted dimension. This best guess selection procedure is sub-optimal at best, and it may become even more problematic when it is used to differentiate facets of a broader construct. In fact, it carries a considerable risk of identifying sets of stimuli with cross-loadings, because facets should be correlated by definition. A dedicated psycholexical study can therefore represent a major improvement over the quality of the stimuli selected and, thus, of the indirect measures. As far as we are aware, this is the first time that a procedure such as this one has been used to select stimuli for the IAT.

\section{Materials and Methods}

Participants. One hundred eighty-one participants ( 76 women, mean age $=22.6$ years, $\mathrm{SD}=3.0)$ from an Italian university took part in the study.

Materials. A list of 64 markers of conscientiousness was assembled from previous studies (Caprara \& Perugini, 1994; Perugini \& Gallucci, 1997; Roberts et al., 2004). These markers were administered in alphabetic order and participants indicated the extent to which each adjective described them on a scale from 1 (it does not describe me at all) to 5 (it describes me completely).

\section{Results}

Data were ipsatized, that is, standardized within subjects, to remove response tendencies (e.g., Ashton, Lee, \& Goldberg, 2004; Hofstee, De Raad, \& Goldberg, 1992), before performing an initial principal component analysis. The first seven eigenvalues were 12.17, 5.73, 2.91, 2.57, 
2.12, 2.02, 1.92, 1.67; the scree-plot therefore suggested a clear elbow after the fourth component. Four components were therefore retained consistent with the aim of this study ${ }^{4}$. The components explained $37 \%$ of the total variance and, after an oblimin rotation, they could be interpreted as orderliness, responsibility, industriousness, and impulse-control. An iterative procedure was then performed to identify the 10 best markers for each of the 4 facets, 5 for the positive and 5 for the negative pole. The main criteria for item selection were: (1) to eliminate adjectives with small loadings (e.g., pedantic was dropped for this reason); (2) to avoid negating adjectives whenever possible (e.g., incautious was dropped for this reason); and (3) to eliminate items with cross-loadings (e.g., conscientious was dropped for this reason).

The loadings of the final solution, which explained $43 \%$ of variance, are reported in Table 1 (Study 1). Markers with substantial primary loadings and no sizeable secondary loadings defined each facet. An exception is the facet responsibility for which some adjectives showed secondary loadings on impulse-control. One of the items, "rash" (sconsiderato), had a slightly larger loading on impulse-control than on responsibility, but it was nonetheless selected for the responsibility IAT, for which the number of items would have been insufficient otherwise. Despite our best efforts, we were only able to identify 39 instead of 40 markers, the missing marker being an adjective for the positive pole of responsibility. To fill in the missing marker, we added on theoretical grounds "dependable" (fidato), which was not present in the original list.

\footnotetext{
${ }^{4}$ Parallel analysis indicated that seven components explained more variance than those extracted from random data (the first random eigenvalues were 2.40, 2.27, 2.17, 2.08, 2.01, 1.94, 1.87, 1.82). Nonetheless, we retained four factors as our aim was to select best markers for the four facets. Note also that while there is a noticeable gap between the first four eigenvalues and the corresponding first four random eigenvalues, subsequently the eigenvalues are very close to each other and do not provide unequivocal strong support for a seven factor solution.
} 


\section{Study 2: Differential roles of conscientiousness facets}

In this study, we built one IAT for each facet of conscientiousness using the stimuli from Study 1 and examined their convergent and discriminant validity (Campbell \& Fiske, 1959). We investigated how facets of conscientiousness, both assessed with direct and with indirect measures, related to different aspects of self-control and to working memory capacity.

\section{Method}

Participants. One hundred and fifty subjects participated in the study for course credit or monetary compensation. Two participants were excluded from all analyses because their pattern of responses (more than $30 \%$ errors in the IAT) indicated random responding. The final sample included 148 subjects (114 females, $M$ age $=22.6$ years, $S D=4.2)$, none of whom participated in Study 1 . The data from five participants (one male and four female students) were discarded from the analyses involving the Automated Operation Span Task (A-OSPAN), because they committed too many errors in the mathematical task (see below). Two female participants were discarded from the analyses involving the behavioral indicators and the peer-reports, because they did not return these questionnaires (see Procedure).

Measures. We assessed conscientiousness facets using four IATs, three self-report scales, one peer-report instrument, and a questionnaire with behavioral indicators. We also measured working memory capacity and self-control.

IATs. Four IATs were administered; these assessed orderliness, impulse-control, industriousness, and responsibility. Participants were instructed to classify words in the categories that were presented in the upper part of the screen using two keys ('E' and 'I'). The target categories were $M e$ vs. Others, whereas the attribute categories in the four different IATs were Controlled vs. Impulsive, Ordered vs. Disordered, Industrious vs. Lazy, Reliable vs. Unreliable. The stimuli were presented individually and in a random order in the middle of the 
screen. The stimuli for the attribute categories were those identified in Study 1, while the stimuli for the target categories were me (me), io (I), mio (mine), mia (mine), miei (mine) for category Me and altri (other), altre (other), essi (they), esse (they), loro (them) for category Others. Table 2 reports the sequence of the blocks for the IAT orderliness; the remaining IATs had an analogous structure. A red X appeared in the middle of the screen for $200 \mathrm{~ms}$ if the participant did not answer correctly (i.e., classified the stimulus in the wrong category), and there was no built-in penalty procedure (Greenwald, Nosek, \& Banaji, 2003). The order of the four IATs, as well as the order of the blocks, were counterbalanced across participants, with half of the participants having the compatible block (e.g., Me-Ordered) and the relative practice trials presented first, and the other half having the incompatible block (e.g., Others-Ordered) presented first. Four D scores (Greenwald et al., 2003) were computed from the combined categorization blocks (Blocks 3 and 5 in Table 2) of each IAT. Latencies below $300 \mathrm{~ms}$ and above $3000 \mathrm{~ms}$ were recoded to 300 and $3000 \mathrm{~ms}$ respectively, error latencies were recoded as the average correct latency in the block plus a $600 \mathrm{~ms}$ penalty. The $\mathrm{D}$ scores were computed by subtracting the average of the transformed latencies in the compatible blocks (i.e., conscientious - me) from the average of the transformed latencies in the incompatible block (i.e., conscientious - others), divided by the standard deviation of the correct latencies in both critical blocks. Additionally, two D scores for each IAT were also computed, one on the odd and one on the even trials, that served as indicators in Confirmatory Factor Analysis (CFA). To minimize the use of response strategies, we used Back and colleagues' (Back et al., 2009) strategy of including a break of 2 minutes between each pair of IATs. During the break, participants were presented with Rorschach pictures and were asked to write down their ideas concerning the inkblot.

Adjective checklist of conscientiousness (ADJ). Participants indicated how each of the 40 adjectives used as stimuli in the IAT described them, on a scale from 1 (it does not describe me at 
all) to 5 (it describes me completely). Four facets were assessed: orderliness, industriousness, impulse-control, and responsibility. Two parcel scores including five items for each facet were also computed to serve as indicators in CFA.

Chernyshencko Conscientiousness Scale (CCS; Green, O’Connor, Gartland, \& Roberts, 2015; Hill \& Roberts, 2011). The 60-item CCS assesses six conscientiousness facets with 10 items each: order (e.g., "I become annoyed when things around me are disorganized"), selfcontrol ("I do not take unnecessary risks"), industriousness ("I have high standards and work towards them”), responsibility ("If I am running late, I try to call ahead to notify those who are waiting for me"), virtue ("If a cashier forgot to charge me for an item I would tell him/her"), and traditionalism ("I support long-established rules and traditions"). Participants indicated their agreement with each statement on a scale from 1 (agree strongly) to 5 (disagree strongly). Note that this questionnaire includes two additional facets, virtue and traditionalism, that have been argued to be lower-level aspects of conscientiousness, although they tend to be recovered less often than the main four facets.

HEXACO-PI (Lee \& Ashton, 2004). We also administered the 32-item conscientiousness scale of the HEXACO-PI (Lee \& Ashton, 2004). Participants indicated their agreement with each statement, on a scale from 1 (strongly disagree) to 5 (strongly agree). Furthermore, a close friend rated the participant using the peer-report form of the same questionnaire. The scale assessed the four facets: prudence, diligence, organization, and perfectionism. A sample item is "I plan ahead and organize things, to avoid scrambling at the last minute".

Behavioral indicators. This scale was adapted from Jackson et al. (2010). Using a scale from 1 (never) to 5 (always), participants indicated the frequency with which they performed each of 50 behaviors ( 25 reversed), 10 for each of five facets: orderliness (e.g., "Used a planner to schedule the day's events"), impulse-control (e.g., "Buy something on a whim"), responsibility 
("Play sick to avoid doing something", reverse-scored), industriousness (e.g., "Put off work until the last minute"), and traditionalism (e.g., "Gave up my bus seat to an elderly person").

Start and stop control scales (De Boer et al., 2011). Participants indicated the extent to which each of 18 statements described them on a scale from 1 (it does not describe me at all) to 5 (it describes me completely). Each aspect of self-control was assessed with 9 items: start-control (e.g., "When there is much distraction, I am able to focus on one thing in order to get it done") and stop-control (e.g., "I can easily stop doing something fun that I know to be bad for me"). Automated Operation Span Task (A-OSPAN; Unsworth et al., 2005). Working memory capacity was assessed with an automatic operation span task (Conway et al., 2005; Turner \& Engle, 1989; Unsworth et al., 2005). In each trial, participants needed to recall series of 3 to 7 letters, in the correct presentation order. Before each letter, a simple math operation (e.g., $(1 \times 2)+$ $1=$ ?) was presented, followed by a possible solution to which participants had to indicate whether it was correct. As recommended by Unsworth and colleagues, participants were explicitly requested to be very accurate in the mathematical operations. Their data were discarded if their accuracy was below $85 \%$. Participants completed three practice blocks followed by 75 test trials. Trials were presented in random order. The A-OSPAN score corresponded to the number of the correctly recalled letters across test trials (Conway et al., 2005).

Procedure. Participants were recruited for a "personality study". Upon arrival, they took part in a series of computerized tasks in a fixed sequence: IATs, CCS, HEXACO-PI, ADJ, and start- and stop- control scales ${ }^{5}$. After completing the session, each participant was given one envelope that included the behavioral indicators questionnaire for the participant to complete and

\footnotetext{
${ }^{5}$ For exploratory purposes, an additional 5-items short scale of perfectionism that we assembled was administered. The psychometric properties of this scale however were not satisfactory and therefore results involving this scale are not considered.
} 
a second envelope that contained the HEXACO-PI peer-report questionnaire. Instructions asked the participants to give the second envelope "to a well acquainted person, for instance to a close friend". The participants returned the envelopes the subsequent week to the experimenter who thanked them, debriefed them, and compensated them.

Analytic Method. We used Principal Component Analysis (PCA) for inspecting the structure of the ADJ scale and on the self-report scales (CCS, HEXACO-PI, ADJ) for computing component scores used in further analyses. We then inspected the multitrait-multimethod (MTMM; Campbell \& Fiske, 1959) correlation matrix to assess convergent and discriminant validity of the IATs with respect to both the ADJ and with respect to the component scores. The ADJ included the same items as the IATs, allowing a more precise control of differences in item content between direct and indirect measures, while the component scores allowed a more heterogenous assessment of conscientiousness facets, since they combined information provided by several measures. These MTMM matrices were also analyzed at the level of latent variables using CFA (e.g., Brown, 2015), as implemented in the R package lavaan (Rosseel, 2012). Convergent validity was established by inspecting whether the monotrait-heteromethod correlations (i.e., the correlations lying on the validity diagonal) were significantly different from zero. Discriminant validity was established by inspecting whether the correlations on the validity diagonal were larger than the correlations lying on the same row and column of the corresponding heterotrait-heteromethod triangles. Heterotrait-monomethod correlations larger than the monotrait-heteromethod ones were not interpreted as a lack of discriminant validity, because high heterotrait correlations are expected from measures that tap into the same personality factor while correlations in the $.20-.30$ range are common between indirect and direct measures of the same construct (Greenwald et al., 2009; Hofmann et al., 2005). For the same reason, our data did not allow a direct computation of latent method factors in CFA: Method 
factors would have been confounded with implicit and explicit conscientiousness factors.

Convergent and discriminant validity was also examined with respect to the peer-reports and to the self-report behavioral indicators.

We used a network approach for examining the relations between conscientiousness facets and other variables considered in the study. The networks were computed with the R package parcor (Krämer et al., 2009) and they were drawn using package qgraph (Epskamp et al., 2015; Epskamp, Cramer, Waldorp, Schmittmann, \& Borsboom, 2012).

\section{Results}

Table 3 reports the correlations among all the measures administered and the reliabilities on the main diagonal. The reliabilities of the self-report scales were generally satisfactory and the reliabilities of the IATs were acceptable, ranging between .60 and .79 .

\section{Preliminary analysis of self-report scales}

PCA on Adjective Checklist items. We replicated the analysis performed in Study 1 on the items of the ADJ. Item "fidato" (trustworty), which had not been considered in Study 1, was also included. The results of this analysis are reported in Table 1 (Study 2). The structure of the ADJ was similar to that emerged in Study 1: The four factors replicated the impulse-control, orderliness, industriousness, and responsibility factors found in Study 1, with some of the responsibility items having cross-loadings with the factor impulse-control. Item "fidato" (trustworthy), that had been added on theoretical grounds, loaded on responsibility as expected.

PCA on self-report scales of conscientiousness (ADJ, CCS, HEXACO-PI). Given the heterogeneity in the facets measured by the questionnaires, we did not have strong a-priori expectations on how many general facets could have emerged. We performed a PCA to inspect which self-report facets could be recovered, following a strict empirical criterion to decide how many to retain. While four eigenvalues were larger than one (the first five eigenvalues were 6.05, 
$2.17,1.65,1.00,0.70)$, the scree plot indicated a clear break after the third component, and results of a parallel analysis also clearly suggested to extract three components (the first four random eigenvalues were $1.56,1.41,1.30,1.23)$. The three components could be easily interpreted as impulse-control, industriousness, and orderliness (Table 4, Solution 1). Since some scales did not clearly load on a single component, we iteratively excluded them and repeated the analysis in order to describe the three facets with the simplest possible factor structure (Table 4, Solution 2). We computed the three component scores using the regression method and saved them for the subsequent analyses.

\section{Aim 1: Development of indirect measures of conscientiousness and test of convergent and discriminant validity}

IATs and Adjective Checklist. The first rows and columns of Table 3 report the multitraitmultimethod matrix (Campbell \& Fiske, 1959) of the four facets of conscientiousness assessed using both IAT and the ADJ. The monotrait-heteromethod correlations were all significantly different from zero, their magnitude being in line with the typical correlations between IATs and self-reports (Greenwald et al., 2009; Hofmann et al., 2005; Schmukle et al., 2008), and they were higher than the heterotrait-heteromethod correlaitons lying on the same rows and columns of the heterotrait-heteromethod block.

We fitted a CFA model (Figure 1A) in which the ADJ parcels and the IAT parcels were allowed to load on latent implicit and explicit facets of conscientiousness respectively. The identification of the model was ensured by fixing the latent variances to 1 and the correlations among the latent variables were estimated. The model fitted the data well $\left(\chi^{2}(76)=92.22, p=\right.$ $.099, \mathrm{CFI}=.985, \mathrm{RMSEA}=.038, \mathrm{SRMR}=.045)$. Table 5 reports the correlations among the latent facets, which indicated clear convergent and discriminant validity for all facets with the partial exception of responsibility, since the correlation between explicit and implicit 
responsibility was significant but slightly lower than the correlation between explicit responsibility and implicit impulse-control. The heterotrait-monomethod correlations were generally high both for the implicit and for the explicit facets, with the correlations between industriousness and impulse-control being consistently the lowest in all the heterotraitmonomethod and heterotrait-heteromethod blocks.

To inspect whether the implicit and explicit conscientiousness facets loaded on a general conscientiousness factor, we fitted an additional CFA model (Figure 1B), in which the facets were allowed to load on superordinate implicit and explicit conscientiousness factors. The model fit was reasonable $\left(\chi^{2}(95)=158.38, \mathrm{p}<.001, \mathrm{CFI}=.943, \mathrm{RMSEA}=.067, \mathrm{SRMR}=.073\right)$ and the second-order factor loadings were consistently large on both implicit and explicit conscientiousness factors. Crucially, the implicit and explicit conscientiousness factors correlated significantly $(r=.34, p<.001)$, ruling out the possibility that the loadings on the implicit conscientiousness factor could simply reflect IAT's method variance.

IATs and all self-reports of conscientiousness. The orderliness, impulse-control, and industriousness IATs showed clear convergent and discriminant validity also when compared to the three component scores of the self-report facets (see Table 3). A CFA analysis of convergent and discriminant validity considering all of the self-report scales of orderliness, impulse-control, and industriousness from the CCS, ADJ, and HEXACO-PI is reported in the Supplementary Material S2 and further confirmed the convergent and discriminant validity of the IATs.

Peer-reports and self-report behaviors. Although self- and peer-reports showed satisfactory convergent and discriminant validity, the IATs did not converge with the peer-report scales (all $p$-values $>.25$, see Table 3 for more details). Additionally, while self-reports of conscientiousness correlated with the self-reported behaviors, the pattern of correlations with the IATs was less clear. The orderliness IAT correlated weakly but significantly with the behavioral 
scores of orderliness $(r=.18, p=.026)$ and impulse-control $(r=.16, p=.047)$, while the correlation between the impulse-control IAT and the corresponding behavioral scale was not significant $(r=.14, p=.086)$. Additionally, the industriousness IAT correlated with the behavioral scale for responsibility $(r=.20, p=.013)$. No other significant correlation emerged between the IATs and the behavioral scores ( $p$-values $>.10$, see Table 3 for details).

\section{Aim 2: Conscientiousness and self-control}

Consistent with our predictions, the start and stop control scales showed a differential pattern of correlations with the facets of conscientiousness, both assessed with direct and with indirect measures (Table 6). Across measures, the strongest correlations were between stopcontrol and impulse-control on the one hand, and between start-control and industriousness on the other hand, although the correlation between start control and the industriousness IAT was not significant $(\mathrm{r}=.14, \mathrm{p}=.086)$. The same patterns were also observed when the individual selfreport measures were considered, both between start-control and industriousness scales (correlations ranging between .47 and .48 , all p-values $<.001$ ), and between stop-control and impulse-control scales (correlations ranging between .69 and .73, all $p$-values $<.001$, see Table 3 for details). 


\section{Aim 3: Conscientiousness and working memory}

Working memory capacity was negatively correlated with the orderliness IAT $(r=-.25, p$ $=.003)$, the self-report component score of orderliness $(r=-.26, p=.002)$, and all individual selfreport orderliness facets (all p-values $<.01$, see Table 3 for details), but it was not significantly associated with any other conscientiousness domains, with the exception of responsibility from the ADJ $(r=-.20, p=.017)$.

\section{Aim 4: Network Analysis}

We used network analysis for investigating the differential relationships among conscientiousness facets, self-control, and working memory. Figure 2 shows the adaptive lasso network computed on the IATs, the component scores of the self-report questionnaires, the peerreport scales of the HEXACO-PI, the self-report behaviors, the start- and stop- control scales, and the A-OSPAN score. The network was computed on the 141 participants who completed all of the measures. The values of the partial correlation corresponding to each edge are reported in the Supplementary Materials S3.

The self-reports, self-reported behaviors, and peer-reports generally clustered within each conscientiousness facet. Exceptions were traditionalism and responsibility behaviors and the peer-reported perfectionism that were positioned interstitially between different clusters. The IATs formed a cluster (on the right part of the plot), the impulse-control and the industriousness IATs were connected with the corresponding self-report facets. The three self-report conscientiousness facets were also connected with each other and so were the IATs, with the noticeable exception of a missing connection between industriousness and impulse-control both for the IATs and for the self-reports. This pattern confirms the weak heterotrait-monomethod correlations between industriousness and impulse-control (Table 4). 
The IATs were not connected to any of the self-report behavioral scores. This indicates that, once the other relevant variables in the network were partialled out, the correlations between the IATs and the self-report behaviors ceased to be significant. We further inspected whether the IATs shared unique variance with self-report behaviors after partialling out the three component scores of conscientiousness facets. Only the partial correlation between the industriousness IAT and the responsibility behavioral scale remained significant (partial $r=.19, p=.020$ ), while the correlations between the orderliness IAT and the orderliness behavior (partial $r=.06, p=.487$ ) and that between the orderliness IAT impulse-control behavior (partial $r=.06, p=.468$ ) waned after controlling for direct measures of conscientiousness facets ${ }^{6}$. The fact that a link between the industriousness IAT and the responsibility behavioral scale was missing in the network depends on the stricter control imposed by network analysis, in which other variables than the self-report conscientiousness facets are controlled for.

The start and stop control scales clearly belonged to the industriousness and the impulsecontrol clusters, respectively. Although the impulse-control IAT correlated significantly with stop-control (see Table 3), the corresponding connection was missing in the network. We further inspected the relationship between the IATs and self-control by performing a multiple regression in the prediction of stop-control: After including the three component scores of conscientiousness, the impulse-control IAT ceased to be a significant predictor of stop control $\left(\beta_{\mathrm{IAT}}=.03, p=.780\right)$, the only significant predictor being the impulse-control component score $\left(\beta_{\mathrm{IMC}}=.46, p<.001\right)^{7}$.

\footnotetext{
${ }^{6}$ The pattern of results was substantially similar if the four ADJ scales were partialled out, with the partial correlations being $.20(p=.014)$ between the industriousness IAT and the responsibility behavior, $.08(p=.335)$ between the orderliness IAT and the orderliness behavior, and .13 $(p=.119)$ between the orderliness and the impulse-control behavior.

${ }^{7}$ The pattern of results was the same if the four ADJ scales were controlled for, $\beta_{\text {IAT }}=.13(p=.225), \beta_{\text {IMC }}=.54(p<$ .001).
} 
The IATs and self-report of orderliness were not connected directly, but they had only one common neighbor, namely working memory (node A-OSPAN), to which they were both connected by a negative edge. Importantly, the A-OSPAN was not connected to any other facet in the network, suggesting that this relationship was specific to orderliness. We explored further this result by performing a multiple regression on the working memory capacity score. We entered the component scores of the self-report facets of conscientiousness in the first step and the orderliness IAT in second (Table 7, Analysis 1). The orderliness IAT showed incremental validity over and above the self-reports $\left(\Delta \mathrm{R}^{2}=.04, p=.017\right)$. A similar result was obtained when the ADJ scales were considered instead of the component scores (Table 7, Analysis 2). The fact that the self-report and the indirect scores of orderliness were uniquely connected to A-OSPAN suggests that the variance shared between orderliness and working memory capacity cannot be fully understood by considering only self-reports measures of orderliness.

\section{Discussion}

The main aim of our work was developing four IATs for assessing conscientiousness facets and testing their convergent and discriminant validity. Additionally we aimed at exploring the connections between conscientiousness and self-control and between conscientiousness and working memory, and we showed how network analysis can be used for analyzing complex patterns of relationships in personality research. In the following sections we discuss how our studies fulfilled each aim and suggest how future research on these topics could further expand our results. 


\section{Aim 1: Development of an indirect assessment of conscientiousness and test of convergent and discriminant validity}

The IATs developed here showed convergent and discriminant validity with self-report measures at the facet level. This finding contradicts prior work documenting a lack of convergent and discriminant validity among direct and indirect measures of conscientiousness, when the construct was measured as an entire domain. Our research thus points to the possibility that indirect measures of conscientiousness can systematically converge with self-report measures if the facet level is taken into consideration and the stimuli are carefully selected. This result may also reflect the fact that the associations between the Self and the traits (Back et al., 2009) are, in some cases, more clearly established at the level of specific facets than for the general domain.

Note that the level of precision achieved in this investigation was possible only by using a strategy to identify the best markers of conscientiousness based on the psycholexical methodology used in Study 1. A partial exception to this pattern of results is the responsibility facet. In Study 1, it did not emerge as clearly as the other three factors and in study 2, it could not be recovered as a facet when performing a PCA of all self-reports of conscientiousness and showed less clear discriminant validity. Previous studies showed that responsibility shares a portion of variance also with agreeableness (e.g., Roberts et al., 2004, 2005). One of the possible limitations of this study was not having included indirect and direct measures of agreeableness, which could instead be used in future studies aimed at clarifying the validity of indirect measures of responsibility.

While peer-report questionnaires correlated with the corresponding self-report facets, they did not converge with the IATs. This could reflect the fact that the manifestations of explicit conscientiousness may be more easily observable to others than the manifestations of corresponding implicit facets (e.g., Vazire, 2010). However the lack of convergence between 
IATs and peer-reports may also stem from the fact that in our study only one peer rated each participant on a single measure, namely the HEXACO-PI. Future studies could overcome such limitation and improve the reliability of peer-report indicators by combining assessments by several raters on multiple scales.

The pattern of convergence between the IATs and self-report behaviors was mixed, with only some facets correlating with some of the behavioral scales, while self-reports of conscientiousness correlated with self-reported behaviors. Previous research has shown that the IAT is often a better predictor of spontaneous behaviors than of self-report behaviors (e.g., Back et al., 2009; Perugini \& Leone, 2009). Our studies have established convergent and discriminant validity with self-reports of conscientiousness for at least three IATs. Future research can build upon our work by identifying nonverbal behavioral indicators specific for each of these facets and by performing a thorough investigation of the predictive validity of the IATs that we have developed.

\section{Aim 2: Conscientiousness and self-control}

We explored the relationships between conscientiousness facets and different aspects of self-control (De Boer et al., 2011). Start-control, the proactive component of self-control, characterized more clearly the industriousness facet of conscientiousness, while stop-control, the inhibitive component of self-control, essentially coincided with impulse-control. Stop-control and impulse-control should not be considered as separate constructs, considering for instance that the disattenuated correlation between the component score of impulse-control and the stop-control scale was almost perfect $(\mathrm{r}=.95, \mathrm{p}<.001)$. Industriousness and impulse-control were not directly connected in the networks (see Figure 2) and showed generally lower correlations with each other than with other facets (see Tables 3 and 5). This suggests that these two facets may reflect distinguishable mechanisms, but also common mechanisms responsible for their coalescence into 
the same superordinate personality dimension. Future research aimed at a precise identification of such mechanisms may build upon our results, which suggest that these facets both share selfcontrol as a common core, but they also seem to rely on different types of self-control (De Boer et al., 2011).

The relationships with self-control were stronger for self-reports than for the IATs, which did not explain additional variance in self-control after controlling for self-report measures of conscientiousness. It is important to notice that in our study self-control was only assessed with self-reports, which tend to have low correlations with nonverbal assessments of self-control (Sharma et al., 2014). An important question for future research is whether a relationship between implicit conscientiousness facets and different aspects of self-control would emerge more clearly if nonverbal assessments of self-control were considered (e.g., Duckworth \& Kern, 2011).

\section{Aim 3: Conscientiousness and working memory capacity}

Results concerning working memory support the hypothesis that facets of conscientiousness have distinct relations with external variables. The A-OSPAN working memory score showed a negative correlation with both indirect and direct measures of orderliness. This relationship may reflect a mechanism that underlies individual differences in orderliness. Organizing one's belongings and tasks might reduce the complexity of the environment and schedule, ultimately decreasing working memory load. Orderliness can be sometimes just a way of storing some pieces of information in the environment (e.g., in agendas and drawers) instead of in memory. If this is the case, orderliness might be especially useful for individuals with low working memory capacity, as an alternative strategy to fulfill their everyday tasks; on the other hand, individuals with a high working memory capacity might be less compelled to be orderly. 
Although a positive relationship between conscientiousness and working memory or executive functions has often been hypothesized (Fleming et al., 2015; Murdock et al., 2013; Williams et al., 2010), the presence of compensatory mechanisms could explain why such positive relationships are so rarely observed empirically. The negative relationship between orderliness and working memory could also be one of the determinants of a more general compensatory mechanism that has been described between conscientiousness and intelligence. According to this view, less intelligent individuals may become more conscientious to cope with their disadvantage (Chamorro-Premuzic \& Furnham, 2004; Moutafi, Furnham, \& Crump, 2006; Moutafi, Furnham, \& Paltiel, 2004; but see Murray, Johnson, McGue, \& Iacono, 2014). One of the limitations of this study was that participants were mostly students, therefore individuals likely to be preselected for both conscientiousness and working memory. Future research should investigate the relationship between conscientiousness and working memory also in samples representative of the general population, to investigate this relationship when full variability is allowed both for conscientiousness and for working memory.

We used a performance-based measure of working memory capacity. Unlike self-reports, such measures are largely unaffected by response tendencies (e.g., Paulhus, Lysy, \& Yik, 1998) and do not require introspection (Nisbett \& Wilson, 1977). Despite these qualities, this performance-based measure does not allow assessing specific features of executive functions. We suggest that future studies should aim at elucidating connections between facets of conscientiousness, both assessed with direct and indirect measures, and facets of the executive functions (e.g., Miyake et al., 2000) -potential compensatory relationships among facets of conscientiousness and facets of executive functioning seem particularly interesting. 


\section{Aim 4: Network Analysis}

We used a network approach, which allowed us to simultaneously estimate the organization among different measures of conscientiousness facets (indirect measures, selfreports, and peer reports) while investigating the interactions of such facets with external constructs. In this research scenario, networks provide (1) a formal way of quantifying the net pairwise relationships among several variables (Krämer et al., 2009), (2) a graphical summary of these relationships (Epskamp et al., 2012), which can be more easily understood even when the pattern of relationships is not a simple one, and (3) a representation that helps the researcher to focus on the differential relationships among variables (e.g., Costantini et al., 2015; Cramer et al., 2012). This is particularly important when one's interest is especially directed towards uncovering personality mechanisms (e.g., Perugini, Costantini, Hughes, \& De Houwer, 2015). Crucially, network analysis can be used in exploratory settings, that is without requiring researchers to put a priori constraints defining which relationships are allowed to vary and which are fixed (Costantini et al., 2015; Krämer et al., 2009). This is the case of some of our results: We could not have anticipated that a connection with working memory capacity would have been specific for facet orderliness or that a connection would be missing between industriousness and impulse-control. Such results may have eluded us without network analysis. Nonetheless the resulting representation is parsimonious, with only a small subset of the possible relationships among the variables being expressed. In the network in Figure 2 for instance, only 30 out of 171 possible edges are present.

Structural equation models (SEM), which have a much longer tradition in personality research, share some of the advantages of network analysis: They allow quantifying the relationships among several variables and they can be represented in a graphically intuitive fashion. Furthermore, they allow controlling for measurement error, while network analysis does 
not include this possibility yet. Although SEM have been adapted to incorporate exploratory measurement models (Asparouhov \& Muthén, 2009; Marsh, Morin, Parker, \& Kaur, 2014), such techniques are generally more appropriate for confirmatory research (i.e., with preregistered hypotheses), while in exploratory settings they often allow for too many degrees of freedom on the side of the researcher (Wagenmakers, Wetzels, Borsboom, van der Maas, \& Kievit, 2012). In network analysis performed with the adaptive lasso method, the presence or the absence of a relationship is established in a data-dependent manner; therefore this method does not include the same degrees of freedom while still providing a parsimonious account of the relationships among the variables of interest and preventing overfitting (McNeish, in press). In conclusion, we believe that the network approach may prove a novel and helpful tool to the personality researcher in several situations, especially in a situation when there is interest in (a) potential differential relationships (b) without specific directional hypotheses that could be tested using confirmatory methods such as SEM. Nonetheless network analysis and SEM should not be understood as opposed statistical approaches: Some of the most promising developments in both SEM and network analysis are likely to come from the union of these methods (Epskamp, Maris, Waldorp, \& Borsboom, in press).

\section{Conclusions}

Taken together, all the results support differential relationships of conscientiousness facets with other personality aspects or executive functions. Current reasoning and psychometric practice common in the scientific literature on personality assumes that questionnaire items, and facet scores defined on them, reflect a common latent variable. This makes items exchangeable psychometric indicators of facets, and facets exchangeable indicators of a superordinate personality domain. We have mounted empirical evidence to show that, at least for the conscientiousness construct, this assumption may be mistaken. Facet scores showed divergent 
and theoretically plausible associations with working memory and self-control. This suggests that distinguishing between personality subdomains may be more important than several personality researchers have hitherto assumed.

To conclude, the combination of different assessment and data analysis methods document differential relationships of conscientiousness facets. The results obtained are encouraging and suggest that such multi-method approaches might be useful for investigating other personality factors than conscientiousness. Considering the facet level rather than the global level might help to shed new light on the underlying mechanisms of personality. 


\section{References}

Asendorpf, J. B., Banse, R., \& Mücke, D. (2002). Double dissociation between implicit and explicit personality self-concept: The case of shy behavior. Journal of Personality and Social Psychology, 83(2), 380-393. doi:10.1037//0022-3514.83.2.380

Ashton, M. C. (1998). Personality and job performance: The importance of narrow traits. Journal of Organizational Behavior, 19(3), 289-303. doi:10.2307/3100173

Ashton, M. C., \& Lee, K. (2005). A defence of the lexical approach to the study of personality structure. European Journal of Personality, 19(1), 5-24. doi:10.1002/per.541

Ashton, M. C., Lee, K., de Vries, R. E., Perugini, M., Gnisci, A., \& Sergi, I. (2006). The HEXACO model of personality structure and indigenous lexical personality dimensions in Italian, Dutch, and English. Journal of Research in Personality, 40(6), 851-875. doi:10.1016/j.jrp.2005.06.003

Ashton, M. C., Lee, K., \& Goldberg, L. R. (2004). A hierarchical analysis of 1,710 English personality-descriptive adjectives. Journal of Personality and Social Psychology, 87(5), 707-721. doi:10.1037/0022-3514.87.5.707

Ashton, M. C., Lee, K., Perugini, M., Szarota, P., de Vries, R. E., Di Blas, L., ... De Raad, B. (2004). A six-factor structure of personality-descriptive adjectives: Solutions from psycholexical studies in seven languages. Journal of Personality and Social Psychology, 86(2), 356-366. doi:10.1037/0022-3514.86.2.356

Asparouhov, T., \& Muthén, B. (2009). Exploratory structural equation modeling. Structural Equation Modeling: A Multidisciplinary Journal, 16(3), 397-438. doi:10.1080/10705510903008204

Back, M. D., Schmukle, S. C., \& Egloff, B. (2009). Predicting actual behavior from the explicit and implicit self-concept of personality. Journal of Personality and Social Psychology, 97(3), 533-548. doi:10.1037/a0016229

Baddeley, A. (1992). Working memory. Science, 255(5044), 556-559. doi:10.1126/science. 1736359

Baddeley, A., \& Hitch, G. (1974). Working memory. In G. H. Bower (Ed.), The psychology of learning and motivation: Advances in research and theory (pp. 47-89). New York: Academic Press.

Bar-Anan, Y., \& Nosek, B. (2014). A comparative investigation of seven indirect attitude measures. Behavior Research Methods, 46(3), 668-688. doi:10.3758/s13428-013-0410-6

Barrick, M. R., \& Mount, M. K. (1991). The Big Five personality dimensions and job performance: a meta-analysis. Personnel Psychology, 44(1), 1-26. doi:10.1111/j.17446570.1991.tb00688.x 
Baumeister, R. F., Vohs, K. D., \& Tice, D. M. (2007). The strength model of self-control. Current Directions in Psychological Science, 16(6), 351-355. doi:10.1111/j.14678721.2007.00534.x

Blanton, H., Jaccard, J., Gonzales, P. M., \& Christie, C. (2006). Decoding the implicit association test: Implications for criterion prediction. Journal of Experimental Social Psychology, 42, 192-212. doi:10.1016/j.jesp.2005.07.003

Bluemke, M., \& Friese, M. (2006). Do features of stimuli influence IAT effects? Journal of Experimental Social Psychology, 42(2), 163-176. doi:10.1016/j.jesp.2005.03.004

Bogg, T., \& Roberts, B. W. (2004). Conscientiousness and health-related behaviors: A metaanalysis of the leading behavioral contributors to mortality. Psychological Bulletin, 130(6), 887-919. doi:10.1037/0033-2909.130.6.887

Brown, T. A. (2015). CFA of Multitrait-Multimethod Matrices. In Confirmatory Factor Analysis for Applied Research (2nd ed., pp. 186-205). New York: The Guilford Press.

Campbell, D. T., \& Fiske, D. W. (1959). Convergent and discriminant validation by the multitrait-multimethod matrix. Psychological Bulletin, 56(2), 81-105.

doi:10.1037/h0046016

Caprara, G. V., \& Perugini, M. (1994). Personality described by adjectives: The generalizability of the Big Five to the Italian lexical context. European Journal of Personality, 8(5), 357369. doi:10.1002/per.2410080502

Conway, A. R. A., Kane, M. J., Bunting, M. F., Hambrick, D. Z., Wilhelm, O., \& Engle, R. W. (2005). Working memory span tasks: A methodological review and user's guide. Psychonomic Bulletin \& Review, 12(5), 769-786. doi:10.3758/BF03196772

Costa, P. T., \& McCrae, R. R. (1992). Revised NEO Personality Inventory (NEO PI-R) and NEO Five-Factor Inventory (NEO FFI): professional manual. Odessa: Psychological Assessment Resources.

Costa, P. T., \& McCrae, R. R. (1995). Domains and facets: hierarchical personality assessment using the revised NEO personality inventory. Journal of Personality Assessment, 64(1), 2150. doi:10.1207/s15327752jpa6401_2

Costantini, G., Epskamp, S., Borsboom, D., Perugini, M., Mõttus, R., Waldorp, L. J., \& Cramer, A. O. J. (2015). State of the aRt personality research: A tutorial on network analysis of personality data in R. Journal of Research in Personality 54, 13-29. doi:10.1016/j.jrp.2014.07.003

Chamorro-Premuzic, T., \& Furnham, A. (2004). A possible model for understanding the personality-intelligence interface. British Journal of Psychology, 95(2), 249-264. doi:10.1348/000712604773952458 
Cramer, A. O. J., van der Sluis, S., Noordhof, A., Wichers, M., Geschwind, N., Aggen, S. H., ... Borsboom, D. (2012). Dimensions of normal personality as networks in search of equilibrium: you can't like parties if you don't like people. European Journal of Personality, 26(4), 414-431. doi:10.1002/per.1866

Cramer, A. O. J., Waldorp, L. J., Van der Maas, H. L. J., \& Borsboom, D. (2010). Comorbidity: a network perspective. Behavioral and Brain Sciences, 33(2-3), 137-193.

doi:10.1017/S0140525X09991567

De Boer, B. J., Van Hooft, E. A. J., \& Bakker, A. B. (2011). Stop and start control: A distinction within self-control. European Journal of Personality, 25(5), 349-362. doi:10.1002/per.796

De Houwer, J., \& Moors, A. (2010). Implicit Measures: similarity and differences. In B.

Gawronski \& B. K. Payne (Eds.), Handbook of implicit social cognition: Measurement, theory, and applications (pp. 176-193). New York: Guilford Press.

de Nooy, W., Mrvar, A., \& Batagelj, V. (2011). Exploratory social network analysis with Pajek (2nd ed.). Cambridge: Cambridge University Press.

De Raad, B., Barelds, D. P. H., Timmerman, M. E., De Roover, K., Mlačić, B., \& Church, A. T. (2014). Towards a pan-cultural personality structure: input from 11 psycholexical studies. European Journal of Personality, 28(5), 497-510. doi:10.1002/per.1953

De Vries, R. E., \& van Gelder, J.-L. (2013). Tales of two self-control scales: Relations with FiveFactor and HEXACO traits. Personality and Individual Differences, 54(6), 756-760. doi:10.1016/j.paid.2012.12.023

Duckworth, A. L., \& Kern, M. L. (2011). A meta-analysis of the convergent validity of selfcontrol measures. Journal of Research in Personality, 45(3), 259-268. doi:10.1016/j.jrp.2011.02.004

Deutsch, R., \& Strack, F. (2010). Building blocks of social behavior: reflective and impulsive processes. In B. Gawronski \& B. K. Payne (Eds.), Handbook of Implicit Social Cognition (pp. 62-79). New York: Guilford.

Egloff, B., \& Schmukle, S. C. (2002). Predictive validity of an implicit association test for assessing anxiety. Journal of Personality and Social Psychology, 83(6), 1441-1455. doi:10.1037//0022-3514.83.6.1441

Egloff, B., Schwerdtfeger, A., \& Schmukle, S. C. (2005). Temporal stability of the implicit association test-anxiety. Journal of Personality Assessment, 84(1), 82-88. doi:10.1207/s15327752jpa8401_14

Eisenberg, N., Duckworth, A. L., Spinrad, T. L., \& Valiente, C. (2014). Conscientiousness: origins in childhood? Developmental Psychology, 50(5), 1331-1349. doi:10.1037/a0030977 
Ent, M. R., Baumeister, R. F., \& Tice, D. M. (2015). Trait self-control and the avoidance of temptation. Personality and Individual Differences, 74, 12-15.

doi:10.1016/j.paid.2014.09.031

Epskamp, S. (2014). semPlot: Path diagrams and visual analysis of various SEM packages' output. R package version 1.0.1. http://cran.r-project.org/package=semPlot

Epskamp, S. (2015). semPlot: Unified Visualizations of Structural Equation Models. Structural Equation Modeling: A Multidisciplinary Journal, 22(3), 474-483.

doi:10.1080/10705511.2014.937847

Epskamp, S., Costantini, G., Cramer, A. O. J., Waldorp, L. J., Schmittmann, V. D., \& Borsboom, D. (2015). qgraph: Network-based data visualization. R package version 1.3.

Epskamp, S., Cramer, A. O. J., Waldorp, L. J., Schmittmann, V. D., \& Borsboom, D. (2012). qgraph: Network visualizations of relationships in psychometric data. Journal of Statistical Software, 48(4), 1-18.

Epskamp, S., Maris, G., Waldorp, L. J., \& Borsboom, D. (in press). Network Psychometrics. To appear in: Irwing, P., Hughes, D., \& Booth, T. (Eds.), Handbook of Psychometrics. New York: Wiley.

Evans, J. S. B. T. (2008). Dual-processing accounts of reasoning, judgment, and social cognition. Annual Review of Psychology, 59, 255-78. doi:10.1146/annurev.psych.59.103006.093629

Fleming, K. A., Heintzelman, S. J., \& Bartholow, B. D. (2015). Specifying associations between conscientiousness and executive functioning: Mental set shifting, not prepotent response inhibition or working memory updating. Journal of Personality, Advance Online Publication. doi:10.1111/jopy.12163

Friedman, H. S., \& Kern, M. L. (2014). Personality, well-being, and health. Annual Review of Psychology, 65, 719-742. doi:10.1146/annurev-psych-010213-115123

Gawronski, B., \& Bodenhausen, G. V. (2007). Unraveling the processes underlying evaluation: Attitudes from the perspective of the APE model. Social Cognition, 25(5), 687-717. doi:10.1521/soco.2007.25.5.687

Greenwald, A. G., Poehlman, T. A., Uhlmann, E. L., \& Banaji, M. R. (2009). Understanding and using the Implicit Association Test: III. Meta-analysis of predictive validity. Journal of Personality and Social Psychology, 97(1), 17-41. doi:10.1037/a0015575

Gawronski, B., Sherman, J. W., \& Trope, Y. (2014). Two of what? A conceptual analysis of dualprocess theories. In J. W. Sherman, B. Gawronski, \& Y. Trope (Eds.), Dual-process theories of the social mind (pp. 3-19). New York: Guilford Press.

Goldberg, L. R. (1990). An alternative "description of personality": The Big-Five factor structure. Journal of Personality and Social Psychology, 59(6), 1216-1229. doi:10.1037/0022-3514.59.6.1216 
Goldberg, L. R. (1993). The structure of phenotypic personality traits. American Psychologist, 48(1), 26-34. doi:10.1037/0003-066X.48.1.26

Gorman, C. A., Meriac, J. P., Overstreet, B. L., Apodaca, S., McIntyre, A. L., Park, P., \& Godbey, J. N. (2012). A meta-analysis of the regulatory focus nomological network: Workrelated antecedents and consequences. Journal of Vocational Behavior, 80(1), 160-172. doi:10.1016/j.jvb.2011.07.005

Govan, C. L., \& Williams, K. D. (2004). Changing the affective valence of the stimulus items influences the IAT by re-defining the category labels. Journal of Experimental Social Psychology, 40(3), 357-365. doi:10.1016/j.jesp.2003.07.002

Green, J. A., O’Connor, D. B., Gartland, N., \& Roberts, B. W. (2015). The Chernyshenko Conscientiousness Scales: A new facet measure of conscientiousness. Assessment. doi:10.1177/1073191115580639

Greenwald, A. G., Banaji, M. R., Rudman, L. A., Farnham, S. D., Nosek, B. A., \& Mellott, D. S. (2002). A unified theory of implicit attitudes, stereotypes, self-esteem, and self-concept. Psychological Review, 109(1), 3-25. doi:10.1037/0033-295X.109.1.3

Greenwald, A. G., \& Farnham, S. D. (2000). Using the implicit association test to measure selfesteem and self-concept. Journal of Personality and Social Psychology, 79(6), 1022-1038. doi:10.1037/0022-3514.79.6.1022

Greenwald, A. G., McGhee, D. E., \& Schwartz, J. L. K. (1998). Measuring individual differences in implicit cognition: the implicit association test. Journal of Personality and Social Psychology, 74(6), 1464-1480. doi:10.1037//0022-3514.74.6.1464

Greenwald, A. G., Nosek, B. A., \& Banaji, M. R. (2003). Understanding and using the Implicit Association Test: I. An improved scoring algorithm. Journal of Personality and Social Psychology, 85(2), 197-216. doi:10.1037/0022-3514.85.2.197

Greenwald, A. G., Poehlman, T. A., Uhlmann, E. L., \& Banaji, M. R. (2009). Understanding and using the Implicit Association Test: III. Meta-analysis of predictive validity. Journal of Personality and Social Psychology, 97(1), 17-41. doi:10.1037/a0015575

Grumm, M., \& von Collani, G. (2007). Measuring Big-Five personality dimensions with the implicit association test - Implicit personality traits or self-esteem? Personality and Individual Differences, 43(8), 2205-2217. doi:10.1016/j.paid.2007.06.032

Higgins, E. T. (1997). Beyond pleasure and pain. American Psychologist, 52(12), 1280-1300. doi:10.1037/0003-066X.52.12.1280

Hill, P. L., \& Roberts, B. W. (2011). The role of adherence in the relationship between conscientiousness and perceived health. Health Psychology, 30(6), 797-804. doi: $10.1037 / \mathrm{a} 0023860$ 
Hofmann, W., Gawronski, B., Gschwendner, T., Le, H., \& Schmitt, M. (2005). A meta-analysis on the correlation between the implicit association test and explicit self-report measures. Personality \& Social Psychology Bulletin, 31(10), 1369-1385. doi:10.1177/0146167205275613

Hofstee, W. K. B., De Raad, B., \& Goldberg, L. R. (1992). Integration of the Big Five and circumplex approaches to trait structure. Journal of Personality and Social Psychology, 63(1), 146-163. doi:10.1037/0022-3514.63.1.146

Hopkins, A. L. (2008). Network pharmacology: the next paradigm in drug discovery. Nature Chemical Biology, 4(11), 682-690. doi:10.1038/nchembio.118

Iori, G., De Masi, G., Precup, O. V., Gabbi, G., \& Caldarelli, G. (2008). A network analysis of the Italian overnight money market. Journal of Economic Dynamics and Control, 32(2007), 259-278. doi:10.1016/j.jedc.2007.01.032

Jackson, J. J., Bogg, T., Walton, K. E., Wood, D., Harms, P. D., Lodi-Smith, J., ... Roberts, B. W. (2009). Not all conscientiousness scales change alike: A multimethod, multisample study of age differences in the facets of conscientiousness. Journal of Personality and Social Psychology, 96(2), 446-459. doi:10.1037/a0014156

Jackson, J. J., Wood, D., Bogg, T., Walton, K. E., Harms, P. D., \& Roberts, B. W. (2010). What do conscientious people do? Development and validation of the Behavioral Indicators of Conscientiousness (BIC). Journal of Research in Personality, 44(4), 501-511. doi:10.1016/j.jrp.2010.06.005

John, O. P., \& Srivastava, S. (1999). The Big Five trait taxonomy: history, measurement, and theoretical perspectives. In L. Pervin \& O. P. John (Eds.), Handbook of Personality, Theory and Research (2nd ed., pp. 102-138). New York: Guilford Press.

Kern, M. L., \& Friedman, H. S. (2008). Do conscientious individuals live longer? A quantitative review. Health Psychology, 27(5), 505-512. doi:10.1037/0278-6133.27.5.505

Kolaczyk, E. D. (2009). Statistical analysis of network data: methods and models. New York: Springer. doi:10.1007/978-0-387-88146-1

Krämer, N., Schäfer, J., \& Boulesteix, A.-L. (2009). Regularized estimation of large-scale gene association networks using graphical Gaussian models. BMC Bioinformatics, 10, 384. doi:10.1186/1471-2105-10-384

Lanaj, K., Chang, C.-H. D., \& Johnson, R. E. (2012). Regulatory focus and work-related outcomes: a review and meta-analysis. Psychological Bulletin, 138(5), 998-1034. doi:10.1037/a0027723

Lee, K., \& Ashton, M. C. (2004). Psychometric properties of the HEXACO personality inventory. Multivariate Behavioral Research, 39(2), 329-358. doi:10.1207/s15327906mbr3902_8 
Lee, K., \& Ashton, M. C. (2008). The HEXACO personality factors in the indigenous personality lexicons of English and 11 other languages. Journal of Personality, 76(5), 1001-1054. doi:10.1111/j.1467-6494.2008.00512.x

MacCann, C., Duckworth, A. L., \& Roberts, R. D. (2009). Empirical identification of the major facets of conscientiousness. Learning and Individual Differences, 19(4), 451-458. doi:10.1016/j.lindif.2009.03.007

MacDonald, K. B. (2008). Effortful control, explicit processing, and the regulation of human evolved predispositions. Psychological Review, 115(4), 1012-31. doi:10.1037/a0013327

Marsh, H. W., Morin, A. J. S., Parker, P. D., \& Kaur, G. (2014). Exploratory structural equation modeling: an integration of the best features of exploratory and confirmatory factor analysis. Annual Review of Clinical Psychology, 10, 85-110. doi:10.1146/annurev-clinpsy-032813153700

McCabe, D. P., Roediger, H. L., McDaniel, M. A., Balota, D. A., \& Hambrick, D. Z. (2010). The relationship between working memory capacity and executive functioning: evidence for a common executive attention construct. Neuropsychology, 24(2), 222-243. doi:10.1037/a0017619

McNeish, D. (in press). Using lasso for predictor selection and to assuage overfitting: a method long overlooked in behavioral sciences. Multivariate Behavioral Research.

Miyake, A., Friedman, N. P., Emerson, M. J., Witzki, A. H., Howerter, A., \& Wager, T. D. (2000). The unity and diversity of executive functions and their contributions to complex "frontal lobe" tasks: a latent variable analysis. Cognitive Psychology, 41(1), 49-100. doi:10.1006/cogp.1999.0734

Moon, H. (2001). The two faces of conscientiousness: Duty and achievement striving in escalation of commitment dilemmas. Journal of Applied Psychology, 86(3), 533-540. doi:10.1037//0021-9010.86.3.533

Mõttus, R., Realo, A., Allik, J., Esko, T., Metspalu, A., \& Johnson, W. (2015). Within-Trait Heterogeneity in Age Group Differences in Personality Domains and Facets: Implications for the Development and Coherence of Personality Traits. PLOS ONE, 10(3), e0119667. doi:10.1371/journal.pone.0119667

Moutafi, J., Furnham, A., \& Crump, J. (2006). What facets of openness and conscientiousness predict fluid intelligence score? Learning and Individual Differences, 16(1), 31-42. doi:10.1016/j.lindif.2005.06.003

Moutafi, J., Furnham, A., \& Paltiel, L. (2004). Why is conscientiousness negatively correlated with intelligence? Personality and Individual Differences, 37(5), 1013-1022. doi:10.1016/j.paid.2003.11.010 
Muraven, M., \& Baumeister, R. F. (2000). Self-regulation and depletion of limited resources: Does self-control resemble a muscle? Psychological Bulletin, 126(2), 247-259. doi:10.1037/0033-2909.126.2.247

Murdock, K. W., Oddi, K. B., \& Bridgett, D. J. (2013). Cognitive correlates of personality. Links between executive functioning and the Big Five personality traits. Journal of Individual Differences, 34(2), 97-104. doi:10.1027/1614-0001/a000104

Murray, A. L., Johnson, W., McGue, M., \& Iacono, W. G. (2014). How are conscientiousness and cognitive ability related to one another? A re-examination of the intelligence compensation hypothesis. Personality and Individual Differences, 70, 17-22. doi:10.1016/j.paid.2014.06.014

Newman, M. E. J. (2010). Networks: an introduction. New York: Oxford University Press.

Nisbett, R. E., \& Wilson, T. D. (1977). Telling more than we can know: Verbal reports on mental processes. Psychological Review, 84(3), 231-259. doi:10.1037/0033-295X.84.3.231

Nosek, B. A. (2007). Implicit-explicit relations. Current Directions in Psychological Science, 16(2), 65-69. doi:10.1111/j.1467-8721.2007.00477.x

O’Connor, M. C., \& Paunonen, S. V. (2007). Big Five personality predictors of post-secondary academic performance. Personality and Individual Differences, 43(5), 971-990. doi:10.1016/j.paid.2007.03.017

Paulhus, D. L., Lysy, D., \& Yik, M. (1998). Self-report measures of intelligence: Are they useful as proxy IQ tests? Journal of Personality, 66(4), 525-554. doi:10.1111/1467-6494.00023

Paunonen, S. V. (1998). Hierarchical organization of personality and prediction of behavior. Journal of Personality and Social Psychology, 74(2), 538-556. doi:10.1037//00223514.74.2.538

Paunonen, S. V, \& Ashton, M. C. (2001). Big Five factors and facets and the prediction of behavior. Journal of Personality and Social Psychology, 81(3), 524-539.

doi:10.1037//0022-3514.81.3.524

Paunonen, S. V, \& Ashton, M. C. (2013). On the prediction of academic performance with personality traits: A replication study. Journal of Research in Personality, 47(6), 778-781. doi:10.1016/j.jrp.2013.08.003

Peabody, D., \& De Raad, B. (2002). The substantive nature of psycholexical personality factors: A comparison across languages. Journal of Personality and Social Psychology, 83(4), 983997. doi:10.1037//0022-3514.83.4.983

Perry, S. J., Hunter, E. M., Witt, L. A., \& Harris, K. J. (2010). P = $f($ Conscientiousness $\times$ Ability): Examining the facets of conscientiousness. Human Performance, 23(4), 343-360. doi:10.1080/08959285.2010.501045 
Perugini, M., Costantini, G., Hughes, S., \& De Houwer, J. (2015). A functional perspective on personality. International Journal of Psychology. doi:10.1002/ijop.12175

Perugini, M., \& Gallucci, M. (1997). A hierarchical faceted model of the Big Five. European Journal of Personality, 11(4), 279-301. doi:10.1002/(SICI)10990984(199711)11:4<279::AID-PER282>3.0.CO;2-F

Perugini, M., \& Leone, L. (2009). Implicit self-concept and moral action. Journal of Research in Personality, 43(5), 747-754. doi:10.1016/j.jrp.2009.03.015

Poropat, A. E. (2009). A meta-analysis of the five-factor model of personality and academic performance. Psychological Bulletin, 135(2), 322-338. doi:10.1037/a0014996

Richetin, J., Richardson, D. S., \& Mason, G. D. (2010). Predictive validity of IAT aggressiveness in the context of provocation. Social Psychology, 41(1), 27-34. doi:10.1027/18649335/a000005

Roberts, B. W., Bogg, T., Walton, K. E., Chernyshenko, O. S., \& Stark, S. E. (2004). A lexical investigation of the lower-order structure of conscientiousness. Journal of Research in Personality, 38(2), 164-178. doi:10.1016/S0092-6566(03)00065-5

Roberts, B. W., Chernyshenko, O. S., Stark, S., \& Goldberg, L. R. (2005). The structure of conscientiousness: An empirical investigation based on seven major personality questionnaires. Personnel Psychology, 58(1), 103-139. doi:10.1111/j.17446570.2005.00301.x

Roberts, B. W., Lejuez, C., Krueger, R. F., Richards, J. M., \& Hill, P. L. (2014). What is conscientiousness and how can it be assessed? Developmental Psychology, 50(5), 13151330. doi:10.1037/a0031109

Roberts, B. W., Walton, K. E., \& Bogg, T. (2005). Conscientiousness and health across the life course. Review of General Psychology, 9(2), 156-168. doi:10.1037/1089-2680.9.2.156

Rosseel, Y. (2012). lavaan: An R package for structural equation modeling. Journal of Statistical Software, 48(2), 1-36.

Ruiz, M. A., Pincus, A. L., \& Dickinson, K. A. (2003). NEO PI-R predictors of alcohol use and alcohol-related problems. Journal of Personality Assessment, 81(3), 226-236. doi:10.1207/S15327752JPA8103_05

Saucier, G. (2009). Recurrent personality dimensions in inclusive lexical studies: indications for a big six structure. Journal of Personality, 77(5), 1577-1614. doi:10.1111/j.1467-

6494.2009.00593.x

Saucier, G., Thalmayer, A. G., Payne, D. L., Carlson, R., Sanogo, L., Ole-Kotikash, L., ... Zhou, X. (2014). A basic bivariate structure of personality attributes evident across nine languages. Journal of Personality, 82(1), 1-14. doi:10.1111/jopy.12028 
Schmukle, S. C., Back, M. D., \& Egloff, B. (2008). Validity of the Five-Factor Model for the implicit self-concept of personality. European Journal of Psychological Assessment, 24(4), 263-272. doi:10.1027/1015-5759.24.4.263

Sharma, L., Markon, K. E., \& Clark, L. A. (2014). Toward a theory of distinct types of "impulsive" behaviors: A meta-analysis of self-report and behavioral measures. Psychological Bulletin, 140(2), 374-408. doi:10.1037/a0034418

Soto, C. J., \& John, O. P. (2012). Development of Big Five domains and facets in adulthood: mean-level age trends and broadly versus narrowly acting mechanisms. Journal of Personality, 80(4), 881-914. doi:10.1111/j.1467-6494.2011.00752.x

Steffens, M. C., \& König, S. S. (2006). Predicting spontaneous Big Five behavior with Implicit Association Tests. European Journal of Psychological Assessment, 22(1), 1-8. doi:10.1027/1015-5759.22.1.13

Strack, F., \& Deutsch, R. (2004). Reflective and impulsive determinants of social behavior. Personality and Social Psychology Review, 8(3), 220-247. doi:10.1207/s15327957pspr0803_1

Tangney, J. P., Baumeister, R. F., \& Boone, A. L. (2004). High self-control predicts good adjustment, less pathology, better grades, and interpersonal success. Journal of Personality, 72(2), 271-324. doi:10.1111/j.0022-3506.2004.00263.x

Tibshirani, R. (1996). Regression shrinkage and selection via the lasso. Journal of the Royal Statistical Society. Series B (Methodological), 58(1), 267-288. Retrieved from http://www.jstor.org/stable/2346178

Turner, M. L., \& Engle, R. W. (1989). Is working memory capacity task dependent? Journal of Memory and Language, 28(2), 127-154. doi:10.1016/0749-596X(89)90040-5

Unsworth, N., Heitz, R. P., Engle, R. W., \& Schrock, J. C. (2005). An automated version of the operation span task. Behavior Research Methods, 37(3), 498-505. doi:10.3758/BF03192720

Unsworth, N., Miller, J. D., Lakey, C. E., Young, D. L., Meeks, J. T., Campbell, W. K., \& Goodie, A. S. (2009). Exploring the relations among executive functions, fluid intelligence, and personality. Journal of Individual Differences, 30(4), 194-200. doi:10.1027/16140001.30.4.194

Vazire, S. (2010). Who knows what about a person? The self-other knowledge asymmetry (SOKA) model. Journal of Personality and Social Psychology, 98(2), 281-300. doi:10.1037/a0017908

Vianello, M., Robusto, E., \& Anselmi, P. (2010). Implicit conscientiousness predicts academic performance. Personality and Individual Differences, 48(4), 452-457. doi:10.1016/j.paid.2009.11.019 
Wagenmakers, E.-J., Wetzels, R., Borsboom, D., van der Maas, H. L. J., \& Kievit, R. A. (2012). An agenda for purely confirmatory research. Perspectives on Psychological Science, 7(6), 632-638. doi:10.1177/1745691612463078

Williams, P. G., Suchy, Y., \& Kraybill, M. L. (2010). Five-Factor Model personality traits and executive functioning among older adults. Journal of Research in Personality, 44(4), 485491. doi:10.1016/j.jrp.2010.06.002

Zeigler-Hill, V. (2006). Discrepancies between implicit and explicit self-esteem: implications for narcissism and self-esteem instability. Journal of Personality, 74(1), 119-144. doi:10.1111/j.1467-6494.2005.00371.x

Zhang, B., \& Horvath, S. (2005). A general framework for weighted gene co-expression network analysis. Statistical Applications in Genetics and Molecular Biology, 4(1). doi:10.2202/1544-6115.1128

Zou, H. (2006). The adaptive lasso and its oracle properties. Journal of the American Statistical Association, 101(476), 1418-1429. doi:10.1198/016214506000000735 
Table 1

Factor Loadings of the Conscientiousness Items

\begin{tabular}{|c|c|c|c|c|c|c|c|c|}
\hline \multirow[b]{2}{*}{ Item } & \multicolumn{4}{|c|}{ Study 1} & \multicolumn{4}{|c|}{ Study 2} \\
\hline & IMC & ORD & IND & RES & IMC & ORD & IND & RES \\
\hline Cauto (cautious) & .72 & -.06 & .09 & -.14 & .76 & .08 & -.07 & -.09 \\
\hline Controllato (controlled) & .60 & .06 & -.07 & .06 & .76 & -.02 & -.02 & -.03 \\
\hline Disciplinato (disciplined) & .42 & .21 & -.10 & .31 & .56 & -.05 & .39 & -.19 \\
\hline Prudente (prudent) & .72 & .03 & .01 & .02 & .82 & -.02 & -.09 & -.09 \\
\hline Riflessivo (reflective) & .44 & -.21 & .04 & .17 & .45 & .24 & -.17 & .11 \\
\hline Spericolato (reckless) & -.70 & -.01 & -.11 & -.02 & -.59 & -.02 & -.14 & .31 \\
\hline Sregolato (profligate) & -.56 & -.14 & -.09 & -.16 & -.52 & -.10 & -.27 & .32 \\
\hline Impulsivo (impulsive) & -.68 & .00 & -.04 & .17 & -.66 & -.13 & .19 & .02 \\
\hline Istintivo (instinctive) & -.64 & -.10 & .09 & .09 & -.78 & .00 & .13 & .02 \\
\hline Imprudente (imprudent) & -.64 & -.22 & .00 & .05 & -.73 & -.22 & .17 & -.12 \\
\hline Disordinato (disordered) & .02 & -.84 & .11 & .00 & .01 & -.89 & .19 & -.11 \\
\hline Disorganizzato (disorganized) & .32 & -.53 & -.27 & -.06 & .07 & -.60 & -.16 & .02 \\
\hline Caotico (chaotic) & -.15 & -.62 & .08 & .04 & -.12 & -.78 & .17 & -.12 \\
\hline Approssimato (haphazard) & -.02 & -.54 & -.05 & .05 & -.06 & -.31 & -.43 & .25 \\
\hline Impreciso (imprecise) & .19 & -.56 & -.25 & .04 & .04 & -.56 & -.38 & .14 \\
\hline Preciso (precise) & .10 & 69 & .18 & .06 & .08 & .61 & .30 & -.01 \\
\hline Ordinato (ordered) & .06 & .80 & -.05 & .04 & .03 & .86 & -.15 & .12 \\
\hline Organizzato (organized) & -.06 & .61 & .30 & .15 & .07 & .62 & .16 & .03 \\
\hline Accurato (careful) & .15 & .49 & .30 & .11 & .04 & .55 & .33 & -.11 \\
\hline Pignolo (fussy) & .10 & .61 & -.09 & -.06 & .04 & 68 & .16 & -.15 \\
\hline Pigro (lazy) & -.02 & .00 & -.69 & -.09 & -.01 & -.21 & -.47 & -.14 \\
\hline Svogliato (unwilling) & .00 & -.15 & -.69 & .15 & -.01 & .10 & -.74 & -.04 \\
\hline Sfaticato (layabout) & -.15 & -.11 & -.76 & .02 & .05 & -.15 & -.64 & -.13 \\
\hline Negligente (negligent) & -.14 & .04 & -.47 & -.01 & .18 & -.04 & -.40 & -.20 \\
\hline Incostante (erratic) & -.08 & -.24 & -.45 & -.15 & -.20 & -.15 & -.48 & -.22 \\
\hline Laborioso (hard-working) & .14 & -.06 & .61 & -.04 & .02 & .15 & .58 & .00 \\
\hline Tenace (tenacious) & -.22 & .00 & .54 & .03 & -.14 & .06 & .23 & .40 \\
\hline Industrioso (industrious) & -.08 & -.01 & .40 & -.07 & -.12 & .24 & .51 & .19 \\
\hline Diligente (diligent) & .30 & .14 & .45 & .25 & .31 & .14 & .63 & -.26 \\
\hline Efficace (effective) & -.14 & .11 & .48 & .12 & -.20 & -.18 & .54 & .13 \\
\hline Affidabile (reliable) & .05 & -.09 & .21 & .65 & .27 & .19 & .10 & .54 \\
\hline Attendibile (dependable) & .02 & -.04 & -.03 & .46 & .00 & -.19 & .16 & .27 \\
\hline Rispettoso (respectful) & .42 & -.06 & -.11 & .42 & .37 & -.16 & .17 & .11 \\
\hline Responsabile (responsible) & .35 & .13 & .14 & .37 & .32 & .16 & .15 & .34 \\
\hline Inaffidabile (unreliable) & .12 & -.02 & -.01 & -.54 & .01 & -.16 & -.18 & -.63 \\
\hline Inattendibile (undependable) & .43 & -.08 & .15 & -.68 & .29 & -.01 & .07 & -.52 \\
\hline Sconsiderato (rash) & -.40 & -.11 & .01 & -.33 & -.53 & -.15 & .04 & -.25 \\
\hline Irresponsabile (unaccountable) & -.18 & -.22 & .09 & -.59 & -.49 & .18 & -.03 & -.36 \\
\hline Indolente (sluggish) & -.07 & .09 & -.22 & -.35 & -.30 & .06 & -.24 & -.14 \\
\hline \multirow[t]{2}{*}{ Fidato (trustworthy) } & - & - & - & - & .17 & -.08 & .03 & .54 \\
\hline & \multicolumn{8}{|c|}{ Correlations among principal components } \\
\hline ORD & .15 & & & & .22 & & & \\
\hline IND & .06 & .29 & & & .11 & .22 & & \\
\hline RES & .19 & .16 & .1 & & .01 & -.02 & .18 & \\
\hline
\end{tabular}

Note. IND = industriousness; ORD = orderliness; IMC = impulse-control; RES = responsibility. Principal component loadings with oblimin rotation. Loadings larger than .20 are represented in bold. 
Table 2

Sequence of the Blocks in the IAT for the IAT Orderliness

\begin{tabular}{lllll}
\hline \multirow{2}{*}{ Block } & $N$ of trials & Task & Left key ('E') & Right key ('I') \\
\cline { 3 - 5 } 1 & 20 & Target discrimination & Ordered & Disordered \\
2 & 20 & Attribute discrimination & Me & Others \\
3 & $60+2$ & Initial combined task & Me, Ordered & Others, Disordered \\
4 & 20 & $\begin{array}{l}\text { Reversed target } \\
\text { discrimination }\end{array}$ & Disordered & Ordered \\
5 & $60+2$ & Reversed combined task & Me, Disordered & Others, Ordered \\
\hline $\begin{array}{l}\text { Note. } \\
\text { subsequent three IATs }\end{array}$ &
\end{tabular}


Table 3.

\section{Correlation matrix.}

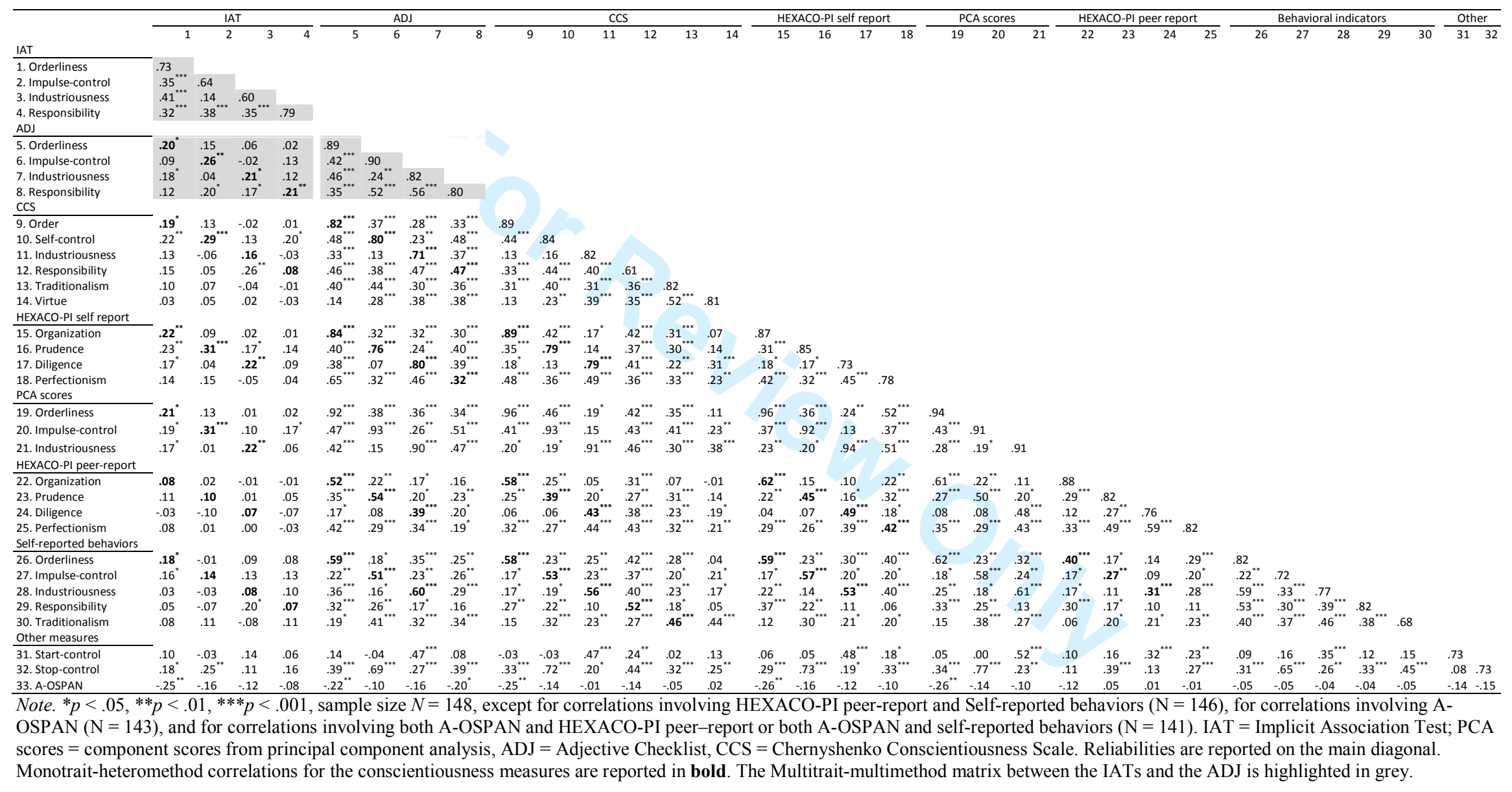


Table 4

Principal Component Analysis of Conscientiousness Scales

\begin{tabular}{|c|c|c|c|c|c|c|c|c|}
\hline & \multicolumn{8}{|c|}{ Component Loadings } \\
\hline & \multicolumn{4}{|c|}{ Solution 1} & \multicolumn{4}{|c|}{ Solution 2} \\
\hline & ORD & IMC & IND & $u^{2}$ & ORD & IMC & IND & $u^{2}$ \\
\hline \multicolumn{9}{|l|}{ CCS } \\
\hline Industriousness & .00 & -.04 & .90 & .20 & -.06 & .00 & .93 & .17 \\
\hline Self-control & .18 & .87 & -.17 & .18 & .08 & .90 & -.01 & .13 \\
\hline Orderliness & .91 & .07 & -.05 & .13 & .97 & .01 & -.07 & .08 \\
\hline Responsibility & .18 & .37 & .38 & .52 & - & - & - & \\
\hline Virtue & -.24 & .52 & .35 & .55 & - & - & - & \\
\hline Traditionalism & .05 & .52 & .21 & .59 & - & - & - & \\
\hline \multicolumn{9}{|l|}{ HEXACO-PI (self-report) } \\
\hline Diligence & .07 & -.11 & .92 & .18 & -.01 & -.05 & .95 & .11 \\
\hline Prudence & .11 & .83 & -.16 & .30 & -.05 & .94 & .03 & .15 \\
\hline Organization & .94 & .01 & -.01 & .12 & .99 & -.05 & -.03 & .07 \\
\hline Perfectionism & .48 & .07 & .41 & .46 & - & - & - & \\
\hline \multicolumn{9}{|l|}{ ADJ } \\
\hline Industriousness & .13 & .04 & .84 & .20 & .10 & .05 & .87 & .17 \\
\hline Impulse-control & .06 & .93 & -.18 & .16 & -.02 & .94 & -.03 & .14 \\
\hline Orderliness & .86 & .08 & .18 & .09 & .84 & .08 & .18 & .11 \\
\hline \multirow[t]{3}{*}{ Responsibility } & -.01 & .55 & .36 & .44 & - & - & - & \\
\hline & \multicolumn{8}{|c|}{ Correlations among components } \\
\hline & ORD & IMC & IND & & ORD & IMC & IND & \\
\hline ORD & 1 & & & & 1 & & & \\
\hline IMC & .37 & 1 & & & .43 & 1 & & \\
\hline IND & .22 & .32 & 1 & 1 & .28 & .19 & 1 & \\
\hline
\end{tabular}




\section{Table 5.}

Correlations among implicit and explicit latent conscientiousness facets.

\begin{tabular}{lllllllll}
\hline & RESi & IMCi & ORDi & INDi & RESe & IMCe & ORDe & INDe \\
\hline RESi & 1 & & & & & & & \\
IMCi & $.58^{* * *}$ & 1 & & & & & & \\
ORDi & $.52^{* * *}$ & $.58^{* * *}$ & 1 & & & & & \\
INDi & $.49^{* * *}$ & .18 & $.62^{* * *}$ & 1 & & & & \\
RESe & $.22^{*}$ & $.25^{*}$ & .12 & $.19^{*}$ & 1 & & & \\
IMCe & .16 & $.37^{* * *}$ & .15 & -.03 & $.57^{* * *}$ & 1 & & \\
ORDe & .06 & $.20^{*}$ & $.27^{*}$ & .11 & $.40^{* * *}$ & $.44^{* * *}$ & 1 & \\
INDe & .14 & .04 & $.24^{*}$ & $.26^{* * *}$ & $.64^{* * *}$ & $.25^{* *}$ & $.53^{* * *}$ & 1
\end{tabular}

Note. $* \mathrm{p}<.05,{ }^{* *} \mathrm{p}<.01,{ }^{* * *} \mathrm{p}<.001$, sample size $\mathrm{N}=148 . \mathrm{RESi}=$ implicit responsibility, $\mathrm{IMCi}=$ implicit impulse-control, ORDi $=$ implicit orderliness, INDi $=$ implicit industriousness, $\mathrm{RESe}=$ explicit responsibility, IMCe $=$ explicit impulse-control, $\mathrm{ORDe}=$ explicit orderliness, $\mathrm{INDe}=$ explicit industriousness. Monotrait-heteromethod correlations are reported in bold. 
Table 6

Correlations Between Self-Control and Conscientiousness Facets

\begin{tabular}{|c|c|c|c|c|c|c|c|}
\hline & \multicolumn{4}{|c|}{ IAT } & \multicolumn{3}{|c|}{ PCA scores } \\
\hline & Orderliness & Impulse-control & Industriousness & Responsibility & Orderliness & Impulse-control & Industriousness \\
\hline Start control & .10 & -.03 & .14 & .06 & .05 & .00 & $.52^{* * *}$ \\
\hline Stop control & $.18^{*}$ & $.25^{* *}$ & .11 & .16 & $.34^{* * *}$ & $.77^{* * *}$ & $.23^{* *}$ \\
\hline
\end{tabular}


Table 7

Hierarchical multiple regression analyses predicting A-OSPAN

\begin{tabular}{ccc}
\hline Predictor & $\mathrm{R}^{2}$ & $\beta$ \\
\hline \multicolumn{3}{c}{ Analysis 1 } \\
Step 1 & $.07(\mathrm{p}=.018)$ & \\
PC-ORD & & $-.24(\mathrm{p}=.011)$ \\
PC-IMC & & $-.04(\mathrm{p}=.656)$ \\
PC-IND & & $-.02(\mathrm{p}=.791)$ \\
Step 2 & $\mathrm{R}^{2}=.11(\mathrm{p}=003)$, & \\
& $\Delta \mathrm{R}^{2}=.04(\mathrm{p}=.017)$ & \\
PC-ORD & & $-.21(\mathrm{p}=.021)$ \\
PC-IMC & & $-.02(\mathrm{p}=.834)$ \\
PC-IND & & $.00(\mathrm{p}=.993)$ \\
IAT-ORD & & $.20(\mathrm{p}=.017)$ \\
& & \\
\hline & & \\
Step 1 & & \\
ADJ-ORD & $.07(\mathrm{p}=.042)$ & $-.19(\mathrm{p}=.052)$ \\
ADJ-IMC & & $.07(\mathrm{p}=.510)$ \\
ADJ-IND & & $.01(\mathrm{p}=.949)$ \\
ADJ-RES & & $-.17(\mathrm{p}=.138)$ \\
& & \\
Step 2 & $\mathrm{R}^{2}=.11(\mathrm{p}=007)$, & \\
ADJ-ORD & $\Delta \mathrm{R}^{2}=.04(\mathrm{p}=.014)$ & $-.16(\mathrm{p}=.095)$ \\
ADJ-IMC & & $.06(\mathrm{p}=.524)$ \\
ADJ-IND & & $.03(\mathrm{p}=.800)$ \\
ADJ-RES & & $-.17(\mathrm{p}=.140)$ \\
IAT-ORD & & $-.21(\mathrm{p}=.014)$ \\
\hline
\end{tabular}

Note. Sample size $N=143$. PC-ORD, PC-IMC, and PC-IND indicate component scores for orderliness, impuls-control, and industriousness respectively; ADJ-ORD, ADJ-IMC, ADJ-IND, and ADJ-RES indicate the orderliness, impulse-control, industriousness, and responsibility scales of the adjective checklist. IAT-ORD $=$ orderliness IAT. 


\section{A. Correlated latent variables}

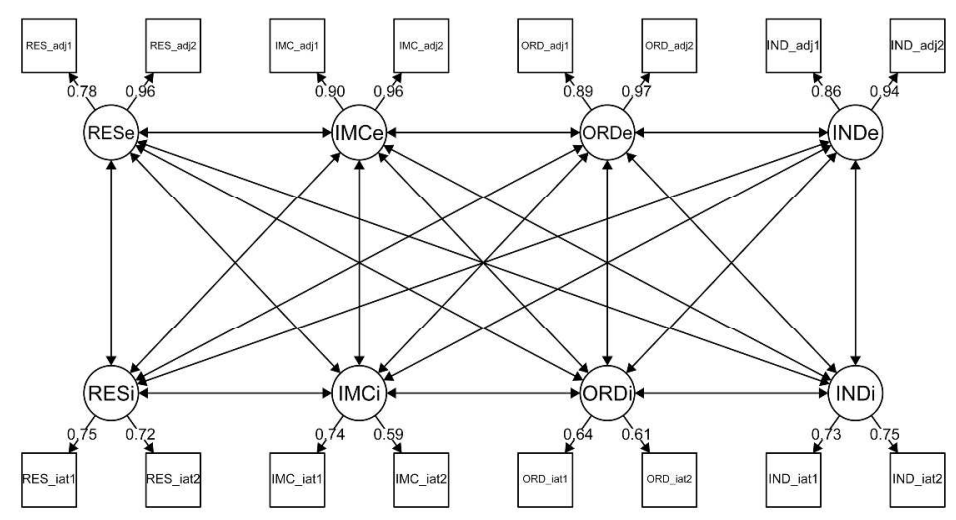

B. Correlated conscientiousness factors

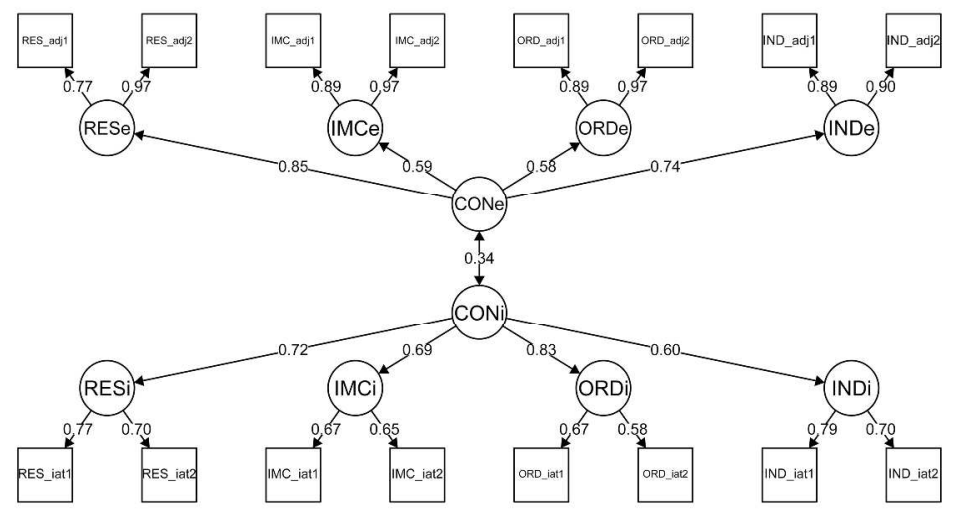

Figure 1. CFA models of implicit and explicit conscientiousness facets.

Circles indicate latent variables and squares indicate observed variables. CONe and CONi indicate the explicit and implicit conscientiousness factors respectively. RESe, IMCe, ORDe, and INDe indicate the explicit responsibility, impulse-control, orderliness, and industriousness facets, while RESi, IMCi, ORDi, and INDi indicate the corresponding implicit facets. For the observed variables, the prefixes indicate the facets, while the suffixes "_iat1" or "_iat2" indicate that the score has been computed on a IAT, and the suffixes "_adj1" and "_adj2" indicate that the score has been computed on the items of the Adjective Checklist. The correlations among latent variables in Figure $1 \mathrm{~A}$ are reported in Table 5 . The figures were obtained with the $\mathrm{R}$ package semPlot (Epskamp, 2014, 2015).

\section{$177 \times 177 \mathrm{~mm}(600 \times 600 \mathrm{DPI})$}




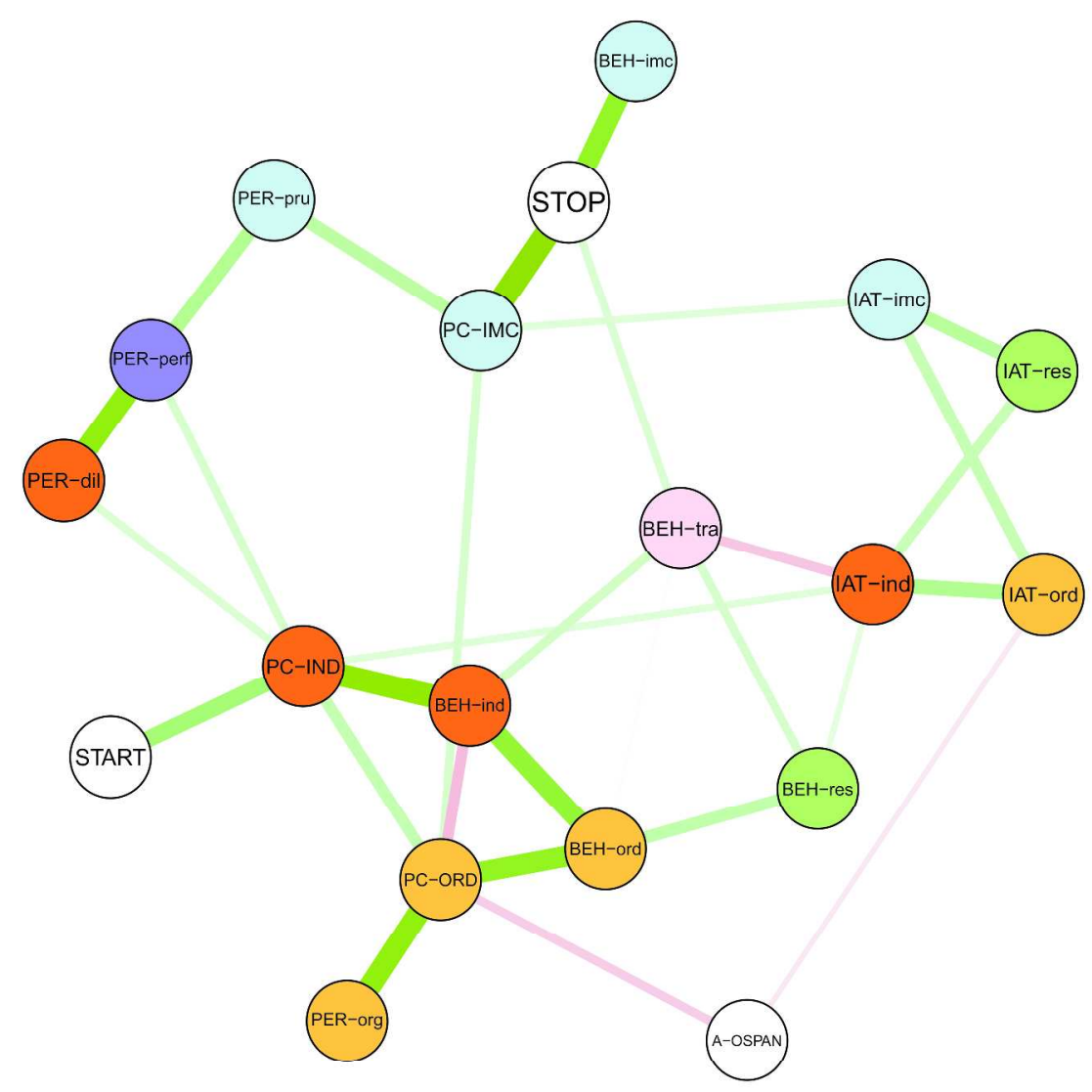

Figure 2. Network of conscientiousness.

The network includes the four IATs, IAT-ord = orderliness, IAT-imc $=$ impulse-control, IAT-ind = industriousness, IAT-res = responsibility; the component scores of self-report questionnaires, PC-ORD = orderliness, PC-IMC = impulse-control, PC-IND = industriousness; the self-reported behaviors, $\mathrm{BEH}$-ord = orderliness, $\mathrm{BEH}$-imc $=$ impulse-control, $\mathrm{BEH}$-ind = industriousness, $\mathrm{BEH}$-res = responsibility, $\mathrm{BEH}$-tra $=$ traditionalism; the peer-reports of the HEXACO-PI scales, PER-org = organization, PER-dili = diligence, PERpru = prudence, PER-perf = perfectionism; the start and stop control scales (START, STOP), and the AOSPAN. Nodes are colored according to facets of conscientiousness, orange $=$ orderliness, blue $=$ impulsecontrol, red = industriousness, green = responsibility, purple $=$ perfectionism, pink $=$ traditionalism.

$177 \times 177 \mathrm{~mm}(600 \times 600 \mathrm{DPI})$ 